\title{
Observations of periglacial landforms in Utopia Planitia with the High Resolution Imaging Science Experiment (HiRISE)
}

\author{
A. Lefort, ${ }^{1}$ P. S. Russell, ${ }^{1}$ N. Thomas, ${ }^{1}$ A. S. McEwen, ${ }^{2}$ C. M. Dundas, ${ }^{2}$ and R. L. Kirk ${ }^{3}$ \\ Received 17 September 2008; revised 5 December 2008; accepted 8 January 2009; published 1 April 2009. \\ [1] The region of western Utopia Planitia $\left(80-105^{\circ} \mathrm{E}, 40-55^{\circ} \mathrm{N}\right)$ displays several types of \\ landforms similar to Earth periglacial features, including scallop-shaped depressions and \\ networks of polygonal terrains. The scalloped depressions have been proposed to originate \\ from thermokarstic processes such as sublimation and/or melting of near-surface ground ice. \\ Using HiRISE imagery, we characterize these depressions and several associated, distinct \\ polygon networks in unprecedented morphologic and topographic detail and investigate \\ support for an ice-based degradation process. The scalloped depressions and interior \\ polygons and ridges are found to evolve together, mainly influenced by sublimation, local \\ proximity of ground ice to the surface, and obliquity variations.
}

Citation: Lefort, A., P. S. Russell, N. Thomas, A. S. McEwen, C. M. Dundas, and R. L. Kirk (2009), Observations of periglacial landforms in Utopia Planitia with the High Resolution Imaging Science Experiment (HiRISE), J. Geophys. Res., 114, E04005, doi:10.1029/2008JE003264.

\section{Introduction}

[2] Water is considered to have played a significant role in shaping the Mars surface environment, especially in the northern lowlands. Utopia Planitia is made particularly intriguing with respect to the potential presence of nearsurface ground ice by a relatively high concentration of periglacial-like geomorphic features and by several hypotheses according to which water may have contributed to the basin from external sources. One of the most prominent types of feature ubiquitous in western Utopia Planitia is a rimless, shallow depression, identified as "scalloped" depression or "scallop." Using new, high-resolution, color, and stereo data from the High Resolution Imaging Science Experiment (HiRISE) [McEwen et al., 2007a] on Mars Reconnaissance Orbiter (MRO) [Zurek and Smrekar, 2007], we focus on these scallops, along with associated polygons, with the goal of constraining their process of formation, and thus providing insight into the role of water in the geologic evolution of the near surface.

[3] We first summarize current evidence and formational theories for an ice-rich, latitude-dependent mantling terrain at mid latitudes, between $30^{\circ}$ and $60^{\circ}$, with specific attention to Utopia Planitia. The meter-scale morphology of scallops and related features are then examined in light of the new data. Morphologies and relationships among features are then used to assess their origins and formational processes, and impli-

\footnotetext{
${ }^{1}$ Space Research and Planetary Sciences, Planetary Imaging Group, Physikalisches Institut, Universität Bern, Bern, Switzerland.

${ }^{2}$ Department of Planetary Sciences, University of Arizona, Tucson, Arizona, USA.

${ }^{3}$ Astrogeology Program, U.S. Geological Survey, Flagstaff, Arizona, USA.

Copyright 2009 by the American Geophysical Union. 0148-0227/09/2008JE003264
}

cations for the local presence, activity, and history of ground ice are discussed.

\subsection{Midlatitude Ground Ice}

[4] The middle and high latitudes in both hemispheres of Mars are today mostly covered by a widespread mantle deposit, as characterized by Mars Orbiter Camera (MOC) [Malin et al., 1992] and Mars Orbiter Laser Altimeter (MOLA) [Smith et al., 2001] data [Kreslavsky and Head, 2000; Mustard et al., 2001]. This terrain is characterized by areas of smooth, relatively flat, deposits, interrupted in places by degradation that implies removed material. The distinctive appearance of this pitted terrain is different from aeolian features [Mustard et al., 2001] and has become referred to as "dissected mantle terrains" (DMT) [Milliken and Mustard, 2003]. In parts where the mantle is intact, its surface appears to be smooth and made of fine material (i.e., sand and small particles such as dust and loess), although boulders have been reported from HiRISE images [Searls et al., 2008]. It covers local high plains and buries, sometimes up to their rims, craters up to $1 \mathrm{~km}$ in diameter. This suggests a thickness up to several 10s of meters in some areas [McBride et al., 2005]. Periglacial-like features are observed within this terrain, although they are not restricted to the DMT and can be found in other types of terrains in the Martian midlatitudes. These include viscous creep and flow features (e.g., lobate debris aprons, concentric crater fill, etc.) [Milliken et al., 2003], polygons similar to those in terrestrial permafrost [e.g., Mangold, 2005], shallow depressions [e.g., Milliken et al., 2003; Morgenstern et al., 2007; Lefort, 2008], and possible pingolike structures [Dundas et al., 2008]. In terrestrial periglacial environments all these features are considered to indicate ground ice [Squyres and Carr, 1986].

[5] The mantle is proposed to have originated from episodes of air fall deposition of ice and dust during periods of high obliquity as recent as 5 Ma ago [Head et al., 2003; Mischna et al., 2003; Levrard et al., 2004; Madeleine et al., 


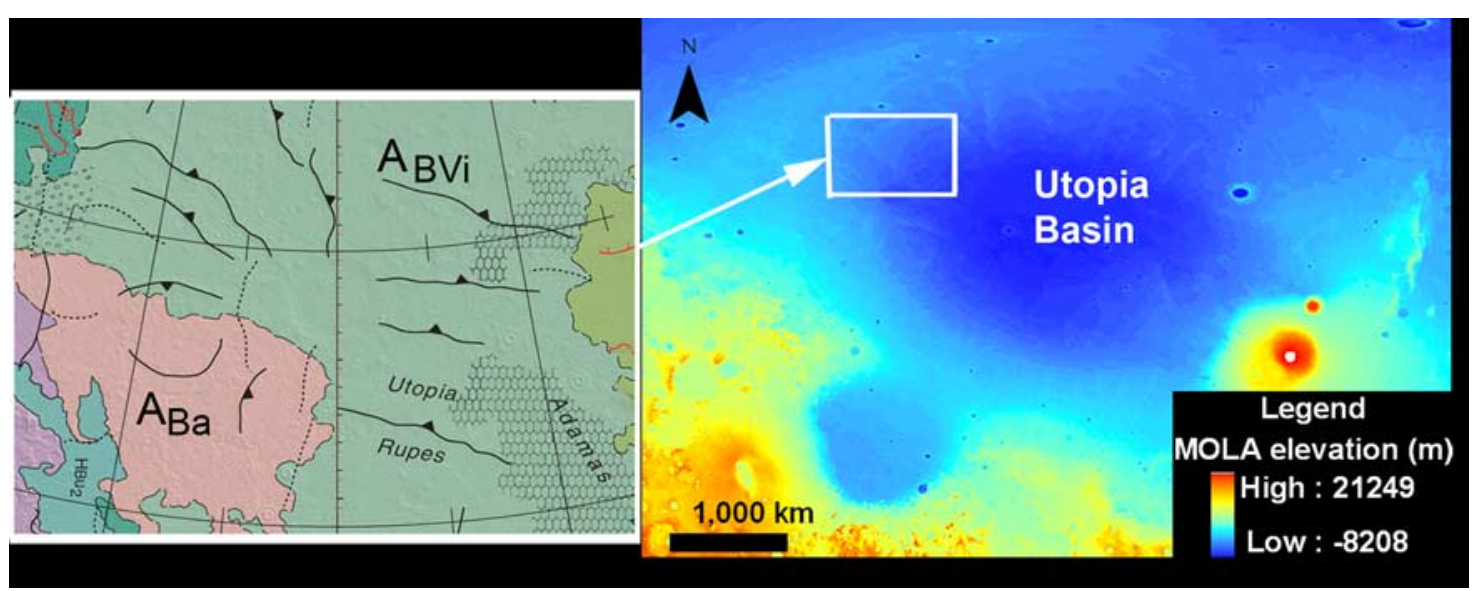

Figure 1. Study area $\left(40-55^{\circ} \mathrm{N}, 80-107^{\circ} \mathrm{E}\right)$. The study area is located in the western part of Utopia Planitia, within the Utopia Basin. It overlays the Astapus Colles unit $\left(\mathrm{A}_{\mathrm{Ba}}\right)$, corresponding to residual volatile-rich mantle or flow material, and the Vasistas Borealis Interior unit $\left(\mathrm{A}_{\mathrm{Bvi}}\right)$, interpreted as Late Hesperian outflow channel sediments, modified by Early Amazonian periglacial-like processes [Tanaka et al., 2005]. This area displays a concentration of periglacial-like features (scalloped depressions, polygons). Adapted from Tanaka et al. [2005].

2007]. Astronomical obliquity changes are thought to drive large-scale redistribution of volatiles over the planet's surface on time scales of $10^{4}$ to $10^{6}$ years [Toon et al., 1980; Pollack and Toon, 1982; Jakosky et al., 1995; Head et al., 2003; Levrard et al., 2004]. Data from the Gamma Ray Spectrometer (GRS), which include the High Energy Neutron Detector (HEND), on Mars Odyssey confirm extensive near-surface hydrogen above $40^{\circ}$ latitude in both hemispheres, with concentrations equivalent to $4 \mathrm{wt} \%$ water at $40^{\circ}$ latitude and ranging up to $20 \mathrm{wt} \%$ at $60^{\circ}$ [Boynton et al., 2002; Feldman et al., 2004; Mitrofanov et al., 2002]. Ice stability models which are consistent with these Odyssey observations predict that any ground ice below $1 \mathrm{~m}$ would generally be stable above $45^{\circ}-55^{\circ}$ latitude in the climate of the presentday [e.g., Mellon and Jakosky, 1993; Mellon et al., 2004; Chamberlain and Boynton, 2007]. According to models examining the effects of varying orbital parameters, ice is more stable at lower latitudes at high obliquity; with a return from high to low obliquity, near-surface ice would become progressively less stable from lower to higher latitudes between $30^{\circ}$ and $60^{\circ}$ [Head et al., 2003; Levrard et al., 2004; Milliken and Mustard, 2003].

[6] Latitude-characteristic erosional morphologies in the DMT are consistent with latitude-dependant degradation of an ice-rich mantle [Mustard et al., 2001; Milliken and Mustard, 2003]. In some DMT areas between $30^{\circ}$ and $50^{\circ}$, the mantle has been totally removed while elsewhere knobby terrains represent intermediate erosion up to $55^{\circ}$ latitude. Systematic relations between the DMT and topography led Searls et al. [2008] to propose that much of the mantle is ice-free except where dissection has occurred. Since the relatively low state of Mars obliquity has been maintained for $\sim 3 \mathrm{Ma}$ [Laskar et al., 2004], this type of near-surface, midlatitude ground ice degradation may continue to operate [Levrard et al., 2004]. It is precisely in these midlatitudes, between 40 and $60^{\circ}$, that scallops are found. However, it is unclear whether the scallops formed in such an ice-rich air fall mantle or in ground that was rich in ice from other processes.

\subsection{Study Area}

[7] In Utopia Planitia, located in the northwest of Utopia Basin, periglacial-like geomorphological features have led observers to suggest that underlying ice-rich sediments must have been deposited there in the past [Kargel and Costard, 1993; Head et al., 2001; Russell and Head, 2003; Tanaka et al., 2005]. The Vastistas Borealis formation (VBF) underlies the area and is interpreted as reworked sediments deposited in the Late Hesperian by a large standing body of water in the northern plains [Head et al., 2001] by outflow channels [Carr, 1996] or by other processes [Tanaka et al., 2003]. In addition, seas or large lakes may have existed in Utopia Basin during the Early Amazonian [Chapman, 1994; Hiesinger and Head, 2000; Kargel and Costard, 1993]. Later, Utopia Basin may have received further water discharges from the Elysium outflow channels [Costard and Kargel, 1995; Russell and Head, 2003]. It has also been suggested that parts of Utopia and Acidalia Planitia could have been occupied by ice sheets leaving glacial sediments [Chapman, 1994; Kargel and Costard, 1993; Kargel et al., 1995]. Whichever water-related events actually did sculpt these terrains, a residue of subsurface water ice could have remained to become a template for permafrost and periglacial processes.

[8] The current surface of western Utopia Planitia is mostly flat, locally pitted and crossed by a polygonal pattern of troughs. The region is characterized by two main geologic units (Figure 1): the Astapus Colles unit (ABa) and the Vastitas Borealis Interior unit $\left(\mathrm{ABv}_{\mathrm{i}}\right)$ [Tanaka et al., 2005]. The $\mathrm{ABa}$ is particularly rich in scalloped depressions and polygonal cracks and is an isolated geological unit overlaying the $\mathrm{ABv}_{\mathrm{i}}$. It forms a flat, smooth mantle that has been partially eroded and is now mostly concentrated inside craters, as well as around crater rims and ejecta deposits [Tanaka et al., 2005]. Almost all craters observable from THEMIS and MOC narrow angle images underlie the mantle, an observation which has been interpreted to indicate formation during the Late Amazonian [Allen and Kanner, 2007; Tanaka et al., 2005]. 


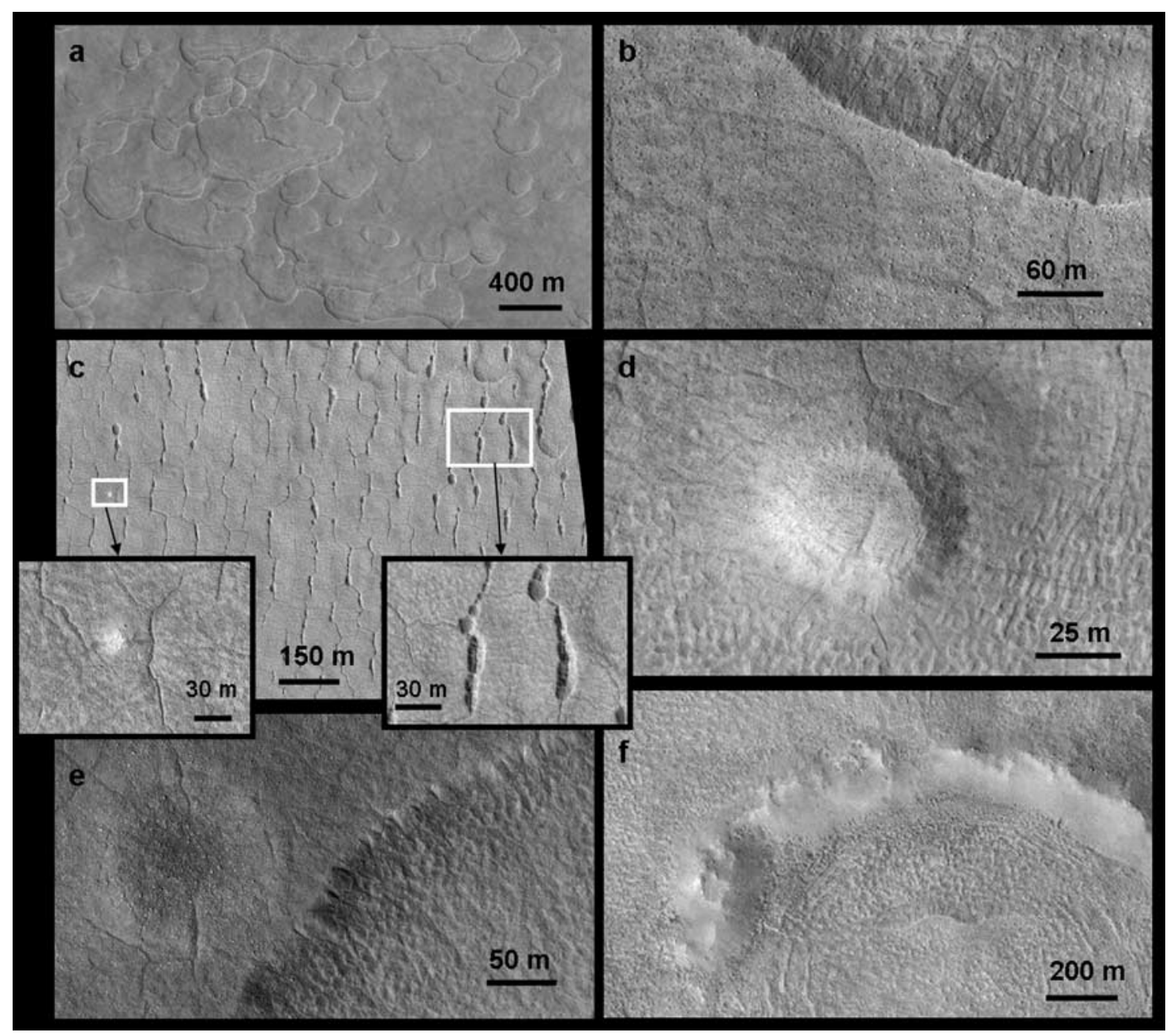

Figure 2. Various types of periglacial-like landforms in Utopia Planitia. (a) Scalloped depressions, a few hundred meters wide, with globally north facing scarps (HiRISE image PSP_001872_2260; $45.637^{\circ} \mathrm{N}$, 93.681 ${ }^{\circ} \mathrm{E}$ ). (b) Polygonal troughs, similar to Earth permafrost polygons. (c and d) Polygon network; pit chains and small mounds reminiscent of the morphology of terrestrial pingo (ice cored hills; HiRISE image PSP_001582_2245; $44.356^{\circ} \mathrm{N}, 86.434^{\circ} \mathrm{E}$ ). (e) Anaglyph of a collapsed mound, possibly a pingo, in which the ice core has melted or sublimed, leading to collapse of the top, or a muted crater, formed in ice-rich substrate (anaglyph made with the HiRISE stereo pair PSP_001938_2265/PSP_002439_2205; 46.031 ${ }^{\circ} \mathrm{N}$, $92.1005^{\circ} \mathrm{E}$ ). (f) Filled crater and fretted terrain (HiRISE image PSP_002439_22 $\overline{6} 5 ; 46.031^{\circ} \mathrm{N}, 92.1005^{\circ} \mathrm{E}$ ).

Periglacial-like features are also observed north and east of the $\mathrm{ABa}$ unit, in surrounding $\mathrm{ABv}_{\mathrm{i}}$. Tanaka et al. [2005] interpret the $\mathrm{ABv}_{\mathrm{i}}$ as being mostly made of Late Hesperian outflow channel sediments, subsequently modified by periglacial processes during the Early Amazonian. The ABvi is also characterized by widely spaced ridges, formed by contractional deformation during the Early Amazonian. The relatively recent latitude-dependent mantle and associated DMT discussed above are emplaced on $\mathrm{ABv}_{\mathrm{i}}$ and may be coincident with some of the ABa materials.

[9] We note that scalloped depressions and other periglaciallike features such as polygons and small mounds are particularly concentrated in the western part of Utopia Planitia. A survey has estimated that $24 \%$ of this region is covered by scalloped depressions [Morgenstern et al., 2007]. On the basis of the analysis of MOC images, Allen and Kanner [2007] observe that 74\% of MOC narrow-angle images of polygons in the northern plains are located in western Utopia
Planitia. Polygons resolved in MOC images are typically $10 \mathrm{~m}$ or larger; HiRISE has shown that smaller polygons are ubiquitous over the northern plains, including western Utopia Planitia. Such a high concentration of polygons suggests that these terrains are a continuous mantle that contains, or once contained, interstitial ice [Seibert and Kargel, 2001; Mangold et al., 2004]. Other periglacial-like landforms in western Utopia Planitia include elongated pits, small buttes, knobby terrain, and several rampart and filled craters (Figure 2). Moreover, the midlatitudinal location of western Utopia Planitia, centered at $\sim 45^{\circ}$, corresponds to the mean, modeled transition latitude for ground ice stability at the current obliquity [e.g., Mellon and Jakosky, 1993], implicating the area as one of possibly active or relatively recent latitudinal mantle erosion. Bearing in mind the combination of geologic features and modeled ice behavior, the scalloped depressions stand out as significant features, ones whose morphology and 


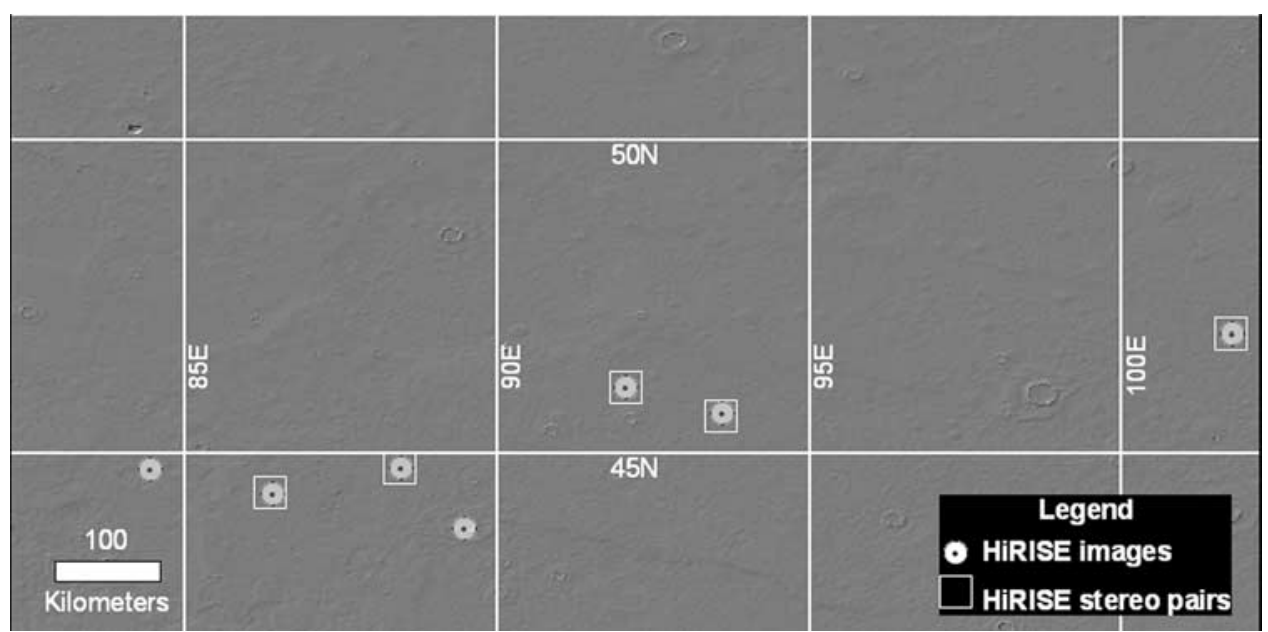

Figure 3. Location of HiRISE images over the study area. We use 14 HiRISE images, including five stereo pairs, distributed over six different sites located between $84^{\circ} \mathrm{E}-102^{\circ} \mathrm{E}$ and $44^{\circ} \mathrm{N}-47^{\circ} \mathrm{N}$.

formation process will likely provide insight into the structure and evolution of the near-surface ice.

[10] The GRS shows that the quantity of hydrogen in the upper ground in western Utopia Planitia is equivalent to only $4 \mathrm{wt} \%$ ice [e.g., Boynton et al., 2002; Feldman et al., 2004]. This value is in accordance with estimates by Kuzmin et al. [2007] who explain changes in the thermal inertia winter values at 40 to $50^{\circ} \mathrm{N}$ by the presence of $3-5 \%$ ice by volume within a surface layer up to $20-30 \mathrm{~cm}$ thick. Thermal inertia values in this area are in the range of $230-330 \mathrm{~J} \mathrm{~m}^{-2} \mathrm{~K}^{-1} \mathrm{~s}^{-1 / 2}$, which corresponds to the typical Mars soil of medium sand to granules (particle diameter 290 to $1200 \mu \mathrm{m}$ ) [Fergason et al., 2006] rather than to ice-cemented soil $\left(2290 \mathrm{~J} \mathrm{~m}^{-2} \mathrm{~K}^{-1} \mathrm{~s}^{-1 / 2}\right)$ [Mellon and Putzig, 2007]. However, since thermal inertia and neutron data only measure the composition at depth scales of a few centimeters to several decimeters, respectively, the composition of deeper underlying layers must be inferred by morphology and theoretical modeling.

\subsection{Data}

[11] Many of the landforms in western Utopia Planitia have been observed by previous instruments, notably MOC. The unique capabilities of the HiRISE imaging system [McEwen et al., 2007a] reveal numerous new features and all in finer detail. We use images obtained in northern autumn and early winter (late 2006-end 2007) prior to MRO orbit 6700 (Table 1), located between 44 and $48^{\circ} \mathrm{N}$ and 83 and $104^{\circ} \mathrm{E}$. Anaglyphs from five stereo pairs and a digital elevation model, with a ground sample distance (GSD) of $1 \mathrm{~m} / \mathrm{pixel}$, were used to study the topography of the scallops [Kirk et al., 2008]. Figure 3 shows the location of these images. We also use MOC images as well as temperature data from the Thermal Emission Imaging System (THEMIS) [Christensen et al., 1992] and digital elevation model and topographic profiles from MOLA to supplement HiRISE observations.

\section{Morphology of the Scalloped Terrains}

[12] Scalloped depressions are among the most remarkable features in western Utopia Planitia. They are rimless, shallow and ovoid in form, ranging from circular to elongate with morphology independent of altitude. Individual scallops range from a few hundred meters to $\sim 3 \mathrm{~km}$ wide and appear isolated or in clusters of varying density. The largest scallops have a knobby floor. Adjoining scallops can form composite depressions of several kilometers in width, inside which thin, sharp ridges can be seen. Neighboring scallops may be at different elevations with respect to each other (Figure 4). Some images show mesas dissected by scallops. These mesas may be made of layered terrains, although erosional processes could also explain this type of morphology (Figure 5). In HiRISE color imagery, the color of the region is very uniform at the scale of meters, with the exception of some steeper slopes which appear "bluer" than the surroundings, probably owing to less dust deposition. Prevalent dust devil tracks suggest aeolian activity in the region. We use the term "upper surface" to describe the surface of the surrounding terrain within which the scallops form, and "scallop interior" for the

Table 1. List of HiRISE Images Used for This Study, Including Stereo Pairs

\begin{tabular}{lcc}
\hline \multicolumn{1}{c}{ Image ID } & $\begin{array}{c}\text { Latitude } \\
\left({ }^{\circ} \mathrm{N}\right)\end{array}$ & $\begin{array}{c}\text { Longitude } \\
\left({ }^{\circ} \mathrm{E}\right)\end{array}$ \\
\hline PSP_002202_2250 & 44.737 & 84.44 \\
PSP_001582_2245; PSP_002848_2245 & 44.356 & 86.434 \\
PSP_002070_2250; PSP_003125_2250 & 44.745 & 88.483 \\
PSP_006606_2240 & 43.8 & 89.5 \\
TRA_005645_2265; PSP_001938_2265; PSP_002439_2265 & 46.031 & 92.1005 \\
PSP_001331_2260 & 45.65 & 93.65 \\
PSP_002162_2260; PSP_001872_2260 & 45.637 & 93.681 \\
PSP_001964_2275; PSP_003177_2275 & 46.961 & 101.829 \\
\hline
\end{tabular}




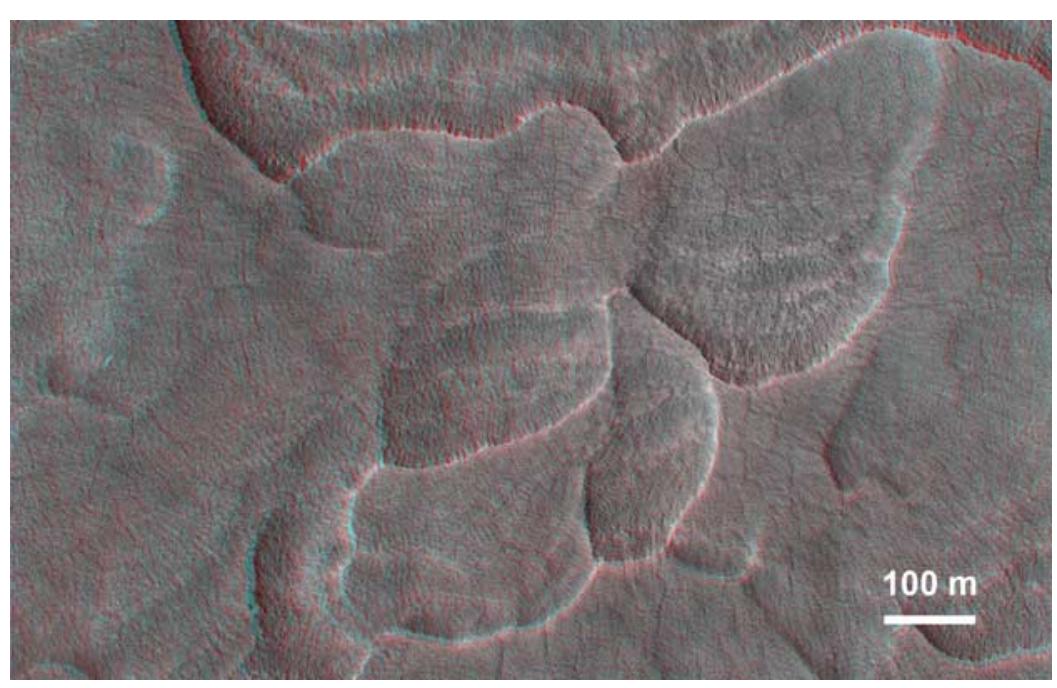

Figure 4. Coalescing scallops at different elevations (anaglyph made from HiRISE stereo pair PSP 002162_2260/PSP_001872_2260; $\left.45.637^{\circ} \mathrm{N}, 93.681^{\circ} \mathrm{E}\right)$.

scalloped depression itself. In certain regions, bumpy terrain (Figure 6) on the upper surface is marked with small, slightly curvilinear, north facing scarps, resembling the plan view shape of smaller scallops. Etched areas of knobby terrain (Figure 5) several hundreds of meters to a few kilometers wide are typically present between groups of scallops.

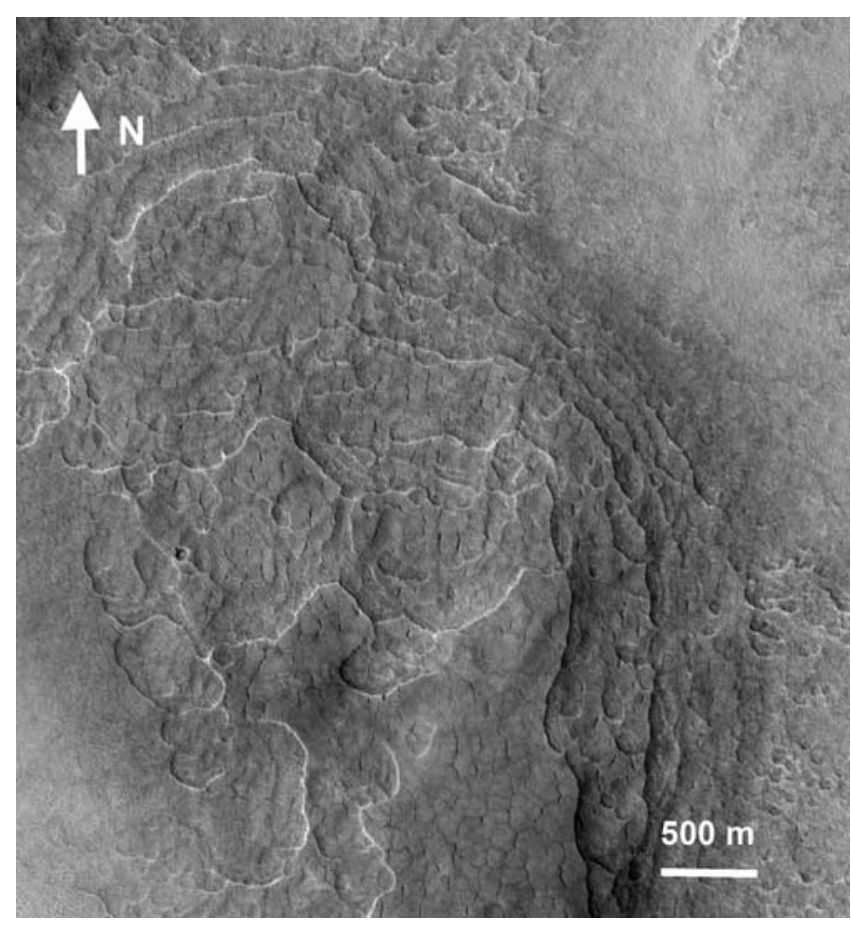

Figure 5. Mesa dissected by scallops. This mesa may consist of several layers dissected by scalloping processes; although, erosional processes alone could also explain this type of morphology. The surface displays polygon cracks and small elongated pits. The zone of knobby and pitted terrain in the top right probably represents the residual terrain left after erosion of the layers (HiRISE image PSP_002070_2250; $\left.44.745^{\circ} \mathrm{N}, 88.483^{\circ} \mathrm{E}\right)$.

\subsection{Scalloped Depressions}

[13] The main feature of a typical scallop is a steep polefacing slope (to which we consistently refer as the "scarp"; Figure 7) which, based on the analysis of a HiRISE digital elevation model (Figure 8), descends between $\sim 5$ and $25 \mathrm{~m}$ from the upper surface to the scallop floor. Opposite to the scarp is a gentle equator-facing slope, sometimes almost flat, and referred to as the "(gentle) rise." More rare are scallops entirely rimmed by steep scarps with bowl-shaped floors. This type forms most often within craters and on crater ejecta, suggesting an effect of the local material upon the formation process. This type is more prevalent in the region $46^{\circ} \mathrm{N}, 92^{\circ} \mathrm{E}$, which is rich in crater ejecta. However, even in these regions, the most common form of scallop morphology remains the asymmetric form. THEMIS maps show temperatures about $10 \mathrm{~K}$ higher on the gentle rise than on the pole-facing scarp, consistent with the relative difference in local angles of solar incidence. Using the HiRISE DEM, we estimate the slope of the pole-facing scarp to be 15 to $30^{\circ}$, while that of the equator-facing rise is typically $\sim 2^{\circ}$. Figure 8 shows the

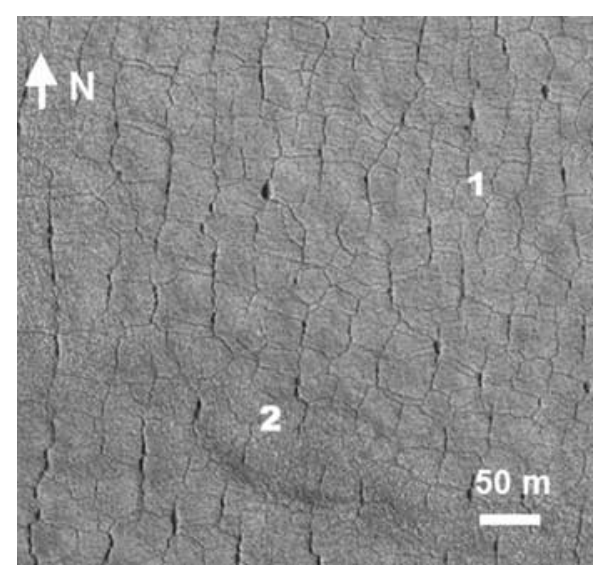

Figure 6. Bumpy terrain (1) and small north facing scarp (2). Illumination is from the bottom left (HiRISE image PSP $\left.001582 \_2245 ; 44.356^{\circ} \mathrm{N}, 86.434^{\circ} \mathrm{E}\right)$. 


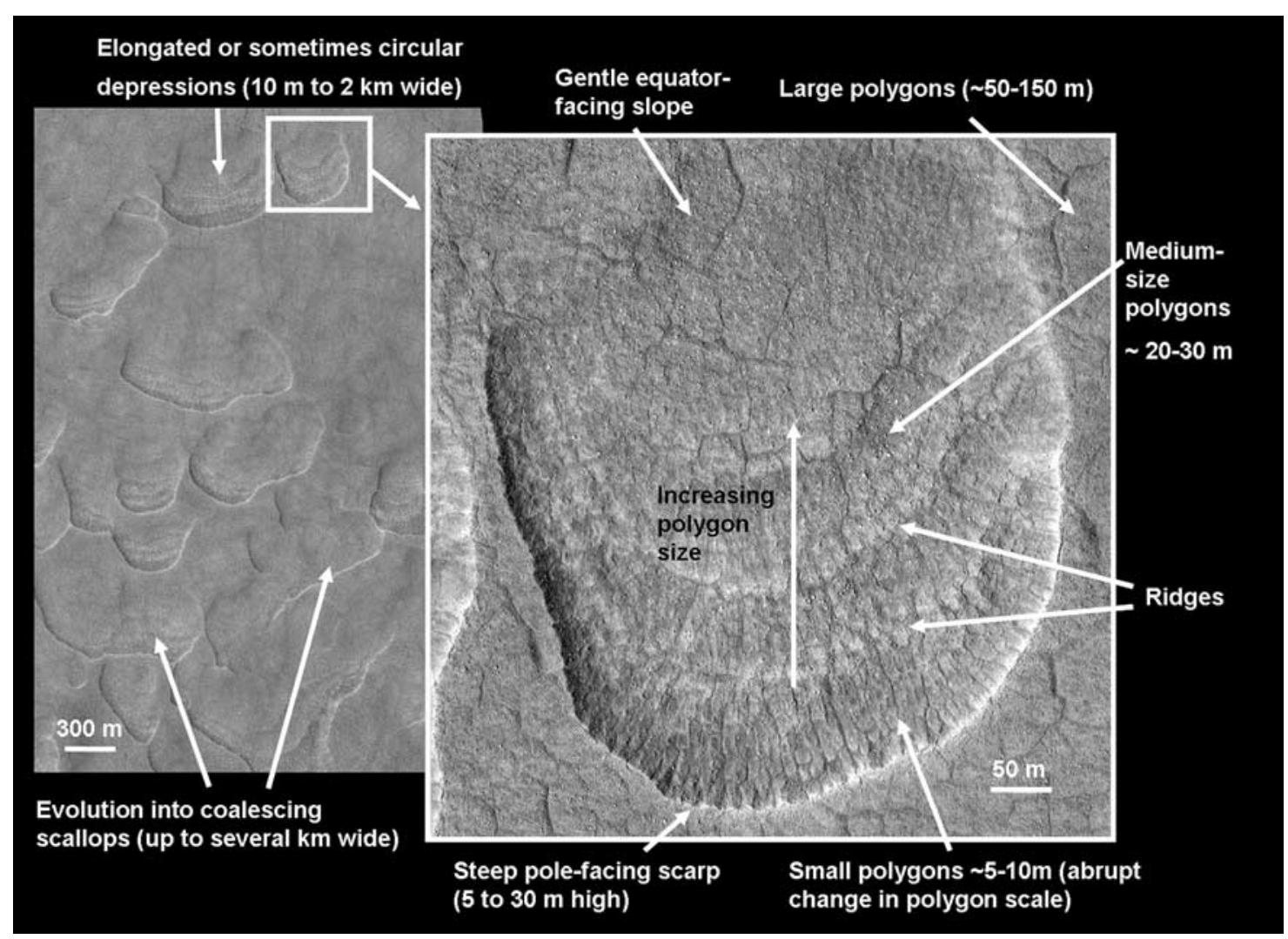

Figure 7. Typical morphology of a scalloped depression. Scallops are elongated depressions that may coalesce. They generally display a pole-facing scarp and an equator-facing gentle slope, with elevations of the floor increasing toward the pole. We observe a series of ridges within the scallop as well as polygons of different sizes: large on the upper surface, small on the scarp, and medium-sized on the scallop floor (HiRISE image PSP_001331_2260; $45.65^{\circ} \mathrm{N}, 93.65^{\circ} \mathrm{E}$ ).

topographic profile of a typical scallop and Figure 9 shows a 3-D perspective of a few scallops. Extending toward the interior from some scarps are small, relatively level promontories a few tens of meters across. Some of these small plateaus display a deflated surface, or are partly separated from the main scarp by fractures, as will be shown later. More rarely, isolated, interior buttes occur near the scarp, lower than the scarp and overlaid by a network of small polygonal troughs. Scallops are typically the same uniform color as the surrounding terrain.

\subsection{Ridges}

[14] On the floors of most scallops greater than $50 \mathrm{~m}$ in diameter are nested series of three to four curvilinear ridges parallel to the pole-facing scarp. The ends of the ridges sometimes converge with those of the scarp, usually at the east and west perimeter. The ridges are 30 to $50 \mathrm{~m}$ wide, several tens to $150 \mathrm{~m}$ apart and up to $3 \mathrm{~m}$ high, forming steps within the scallop (Figures 8 and 9). They are never higher than the upper surface and display a rounded, asymmetrical profile, with the steeper side facing the scarp and sloping at $3^{\circ}$ to $5^{\circ}$.

\subsection{Polygons}

[15] Scallops and surrounding terrain are crossed by a diverse network of polygonal cracks (Figure 7). Polygonal terrains on Earth are often associated with periglacial pro- cesses, although other processes such as desiccation can also produce polygonal patterns. Therefore, their relationship with the scallops is important as a constraint on formation models. HiRISE images reveal a broad polygon scale variation (Figure 10). The upper surface displays a network of relatively large polygons several tens of meters wide whereas a finer, more regular network of polygons on the order of a few meters wide occurs within the scallops, especially on and adjacent to the steep scarps (Figures 7 and 10). Within scallops there is typically a gradational transition between the large polygon network reaching down the gentle rise and the small polygon network on the floor. Essentially, the smalldiameter polygons increase in diameter away from the scarp along the scallop floor to merge with the larger, upper surface polygon network (Figures 7 and 10). Occasionally this transition is more abrupt, making a clear division between the two types of networks in the middle of the scallop.

[16] The large polygons on the upper surface range from 30 to $150 \mathrm{~m}$ across (Figure 11). Crack intersections usually form three-way vertices of $\sim 120^{\circ}$ angles. Polygon interior surfaces are flat or slightly raised compared with their edges, and are often bumpy with rock and dust accumulation. The troughs are well resolved by HiRISE and are typically 2 to $4 \mathrm{~m}$ across. They are $\mathrm{U}$ and $\mathrm{V}$ shaped and filled with dark material. The large troughs are visible on the HiRISE DEM and appear to be up to $1.5 \mathrm{~m}$ deep. 

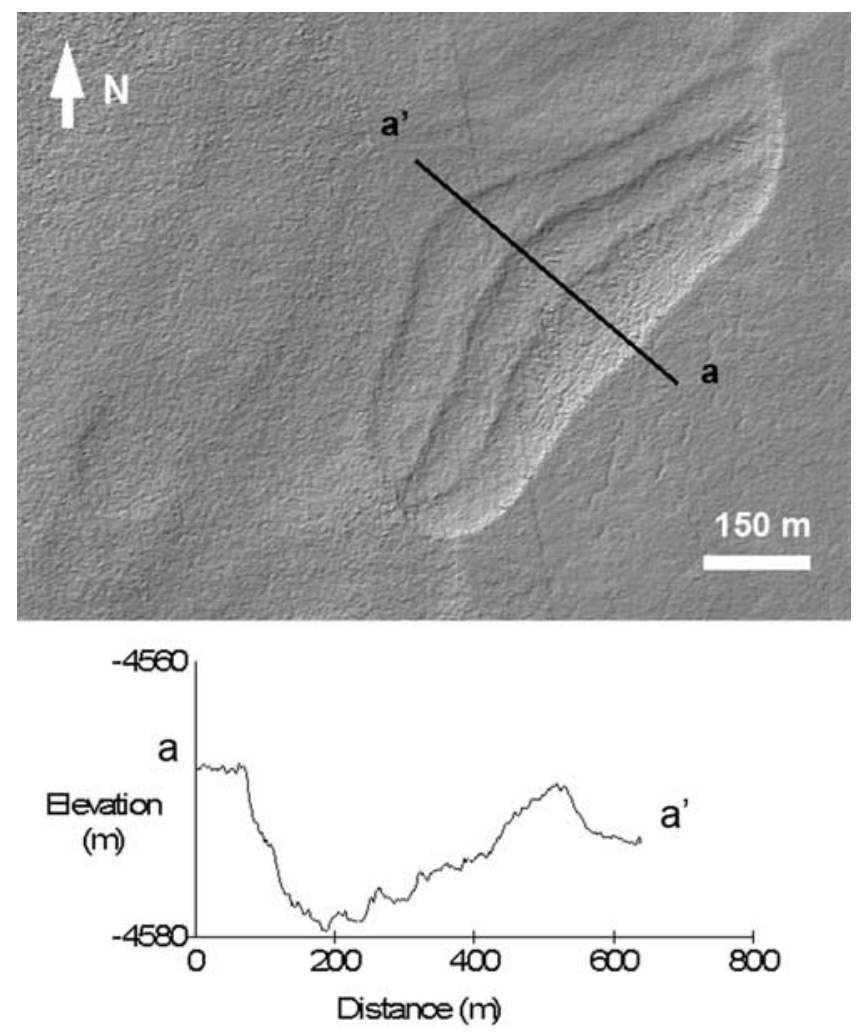

Figure 8. Topographic profile of a scallop. The small (a meter or less) peaks in the profile are not noise but correspond to the polygon troughs. The dark stripe crossing the scallop is an artifact (HiRISE DEM; $46.031^{\circ} \mathrm{N}, 92.1005^{\circ} \mathrm{E}$ ).

[17] The smaller polygon network within the scallop is concentrated more on the lower sections of scarp that meet the scallop floor. The small polygons are more homogeneous in size than the large polygons, ranging from 5 to $10 \mathrm{~m}$ wide (Figures 7 and 10) and up to $50 \mathrm{~cm}$ deep according to the HiRISE DEM. However, the DEM does not resolve features down all the way to the $1 \mathrm{~m}$ GSD so very narrow troughs are likely to be missed out on or underestimated. It is therefore possible that the polygon troughs are actually deeper than estimated above. Not only size, but morphology of the small polygons depends upon their location within the scallop. At the top of some scarps are one or two rows of rectangular polygons, with high centers. The orientation of the troughs is orthogonal and parallel to the slope. The remaining, interior networks are hexagonal polygons with predominantly threeway intersections. There are morphological differences among polygons between the interior ridges, on the interior ridges, and on or near the scarp. Between the ridges, polygons are characterized by low centers, with steep-sided troughs and raised rims (Figure 12a). The polygons on the ridges display high centers and gently sloping sides (Figure 12b). Polygon troughs on the scarp and floor of the scallop are steeper and narrower ( 0.5 to $1 \mathrm{~m}$ wide) than those on the upper surface.

\subsection{Trends in Scallop-Polygon Relations}

[18] Scallop size correlates with the appearance of internal scallop features, such as interior ridges and polygons (Figure 13). Small scallops ( $<100 \mathrm{~m}$ diameter) encompass a shallow depression without ridges or a small polygon network on the scarp. Instead, the large polygon network on the upper surface typically overprints them (Figure 13, stages 3-4). Larger scallops (>100 m diameter) often have an oblong shape, the longer scarps displaying greater curvature and sometimes encircling $>180^{\circ}$ to present an equatorwardfacing aspect at their ends. These scarps overlook deeper depressions, often containing several ridges (Figure 13, stages 5-6). Relatively gently sloped scarps lack the network of small polygons (Figure 13, stage 4) common to steeper scarps (Figure 13,5-6). The largest individual scallops (generally more than $500 \mathrm{~m}$ wide) and the coalescing scallops typically display both ridges and diverse polygons, often intermixed with hummocky terrain.

[19] The large, upper surface polygon network very often overprints smaller, shallower scallops, with no structural disruption of large polygon troughs at either the upper lip of the scarp or the top of the gentle rise. Polygon troughs that intersect larger and deeper scallops discontinue at the scarp edge. In these scallops there is often an abrupt change in polygon scale at the scarp's upper edge toward a small network (Figure 10a), which never crosses the scarp onto the upper surface. From the opposite side, the upper surface polygon network may partially extend down into larger scallops on the gentle rise (Figure 13, stages 5-6). Despite this encroachment, there is usually a clear edge marking the poleward boundary of the gentle, equator-facing rise and the upper surface (Figure 7 and Figure 13, stage 6). This edge is accentuated by the different appearance of polygon troughs on either side. The scallop interior segment of an edgecrossing trough is notably thinner (2 to $3 \mathrm{~m}$ ) compared to the upper surface segment ( 2 to $4 \mathrm{~m}$ ). These polygons on the rise become successively more degraded and infilled and merge with the small polygon network downslope, toward the scallop interior.

\subsection{Additional Features}

\subsubsection{Small Elongated Pits}

[20] In some areas, small circular or elongated pits (Figure 2c) form chains within wide, $\mathrm{N}-\mathrm{S}$ oriented polygon troughs. These pits do not form in the E-W troughs. Their morphology is different from those of scalloped depressions. They are symmetrical with respect to trough centers, range up to $20 \mathrm{~m}$ wide and $150 \mathrm{~m}$ long, occasionally coalesce, have a flat floor, and are apparently shallower than the scalloped depressions. Occasionally, a narrow crack is visible along the center of the pit floor. This floor crack implies either that the pits do not reach to the bottom of a preexisting crack or that crack development continued during or after pit formation. Some pits are observed inside scalloped depressions. These pits have been postulated to be the origin of the formation of scalloped depressions by Morgenstern et al. [2007]. We examine this possibility in section 3.5.1.

\subsubsection{Boulders and Dunes}

[21] One of the more surprising results of HiRISE investigations is that boulders up to $4 \mathrm{~m}$ across are scattered over the surface throughout the study area. They are angular, lighter toned than the surrounding terrain and some of them are partly buried in the ground. The boulders are not preferentially collected within any of the scallops or internal or associated features. The distribution density varies throughout the study area without relation to the local topography 


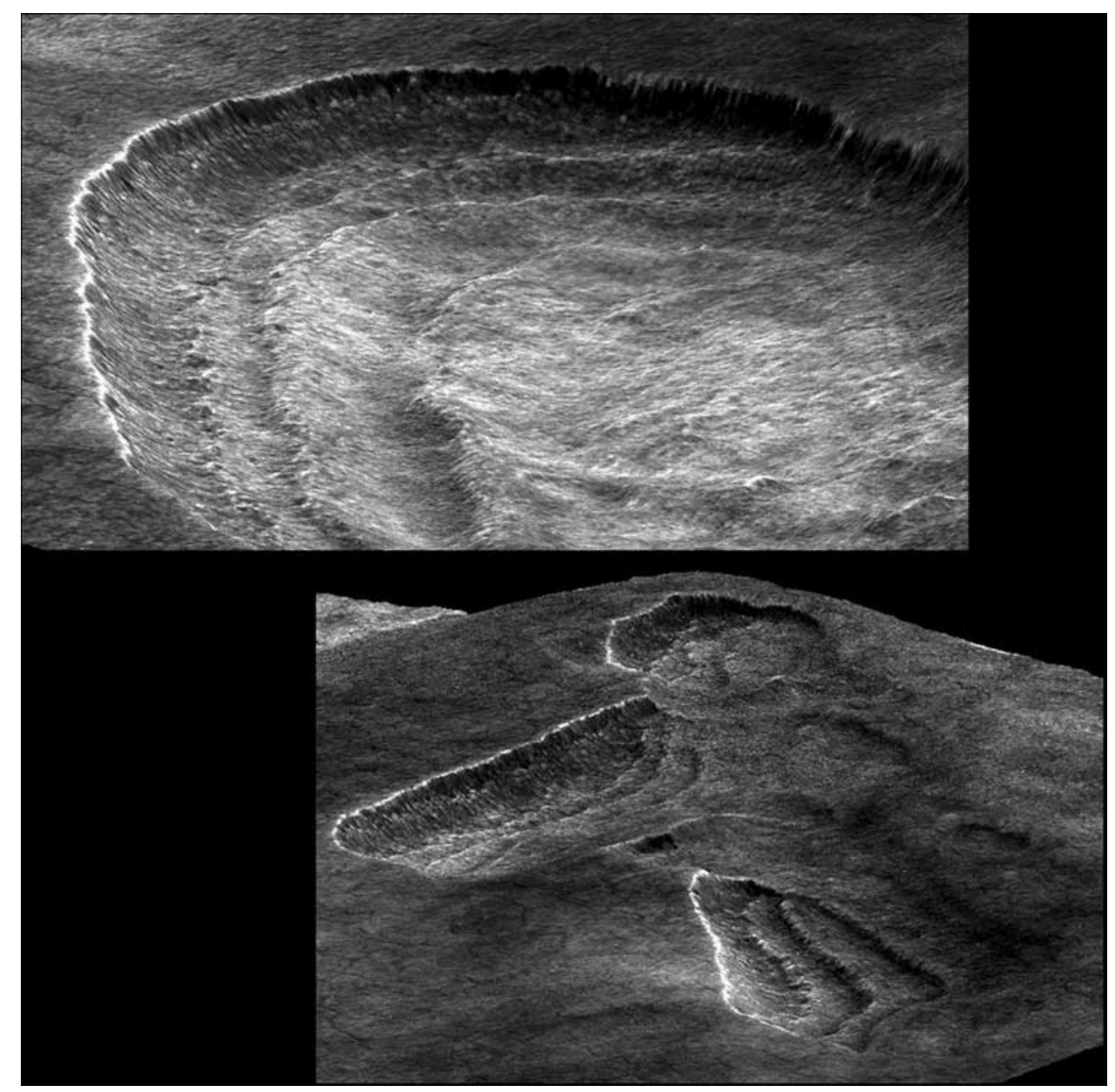

Figure 9. 3-D view of a few scallops. The ridges are asymmetrical with a steeper, shorter, scarp-facing slope and form steps on the scallop floor. The width of the top image is $\sim 800 \mathrm{~m}$; the width of the bottom image is $\sim 1500 \mathrm{~m}$ (HiRISE image PSP_001938_2265 overlaid on a HiRISE DEM).

(Figure 14). In some areas, boulders are also concentrated on and near the rims of small craters, a few hundreds of meters in diameter. A few series of dunes, indifferently located in and outside of the scallops, are also observed throughout the study area.

\section{Formation of Polygons and Scalloped Depressions}

\subsection{Earth Polygons}

[22] On Earth, the most common broad type of periglacial patterned ground is thermal contraction polygons. These polygons initiate as a network of cracks formed by seasonal thermal contraction of ice-rich ground, often in permafrost (permafrost polygons). The depth of the cracks, as well as the size and shape of the polygons, reflects thermal stress, climate conditions and ground properties [Lachenbruch, 1962]. If spring thawing occurs in a near-surface active layer, polygon cracks may be filled by meltwater that freezes again once in contact with the permafrost below. When repeated over 100 to 1000 years this process leads to the formation of ice wedges within the polygon cracks [e.g., Plug and Werner, 2002; French, 2007]. Ice wedge polygons often have low centers and raised rims along steep-sided troughs. The rims are generally considered to be produced by compression of soft sediment during wedge growth. As they grow and the water freezes and expands, an ice wedge will push adjacent silty-icy sediment aside, thus raising the ground surface and producing low rounded rims surrounding a lower polygon center [e.g., Mackay, 1980; French, 2007]. A similar process occurs in dry environments except that loose, windborne surface material may accumulate in the troughs instead of water, producing sand wedge polygons, which have the same morphological characteristics as ice wedge polygons [Murton et al., 2000; Plug and Werner, 2002; Sletten et al., 2003; Levy et al., 2006]. The presence of sediment blown in when the crack is open causes compression along troughs when the surrounding ground expands again. Permafrost polygons may evolve into sublimation polygons through modification by sublimation of interstitial and crack ice. This process results in enlargement of the cracks and shallowing of the crack wall due to collapse of the now-dry, less-cemented wall material. Sublimation polygons typically have high centers (Figure 15). In terrestrial polar regions, polygon networks are a major indicator that water ice is present. The different polygon forms are indicative of specific environmental and climate parameters, including ground material, temperature gradient, ice (water) content and topography [e.g., Lachenbruch, 1962; 


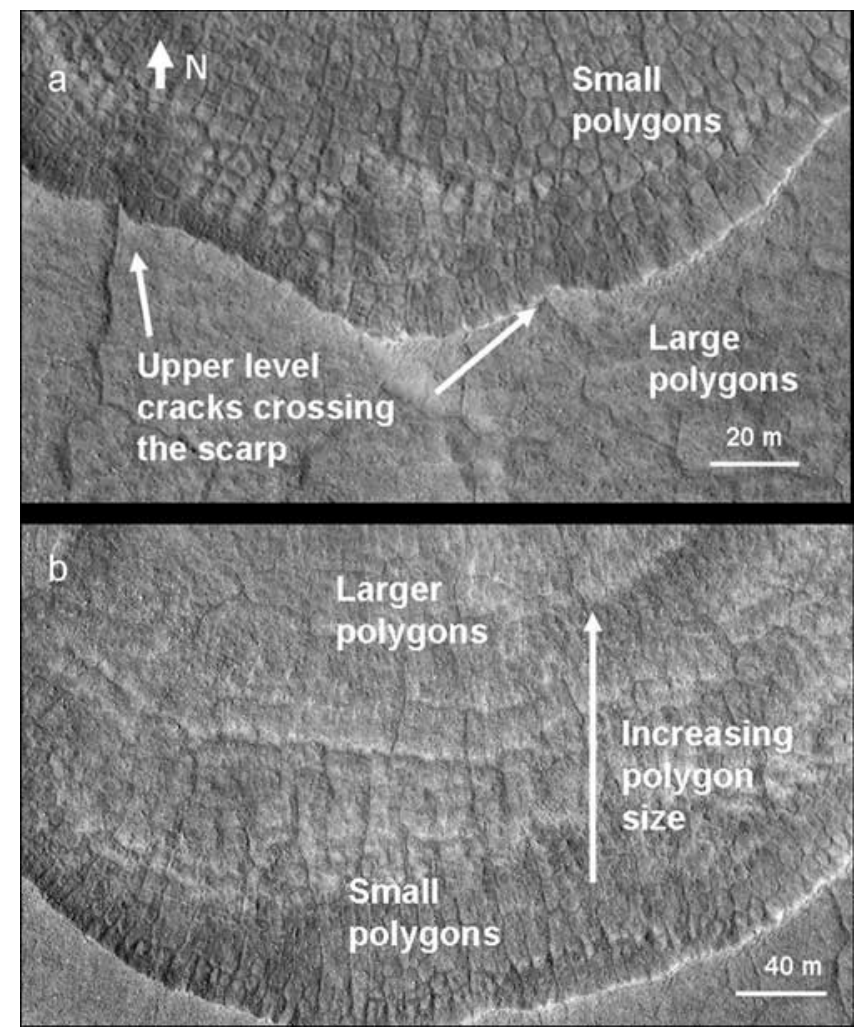

Figure 10. Scale changes within the polygon network. (a) Abrupt scale change at the scarp between the large polygons on the upper surface and the small polygons on the scarp. We notice some upper level cracks that are crossing the scarp. (b) Progressive scale change on the scallop floor, from small polygons on and at the base of the scarp to larger polygons toward the center of the scallop (HiRISE image PSP_002162_2260; $\left.45.637^{\circ} \mathrm{N}, 93.681^{\circ} \mathrm{E}\right)$.
Mellon, 1997; Marchant et al., 2002; Sletten et al., 2003; Mangold, 2005; French, 2007].

\subsection{Utopia Polygons}

[23] The size and shape of the Utopia polygons, as well as their location within supposedly ice-rich terrains, suggest that they are similar to Earth thermal contraction cracks. As with Earth polygons, morphological differences between the polygon networks we observe on Mars should reflect local differences in parameters such as thermal conditions, ground properties, ice table depths or simply age.

3.2.1. Upper Surface Polygons

[24] The u-shaped wall morphology of the wide troughs suggests that the troughs have undergone significant erosion. The presence of material within the troughs is consistent with such degradation as the material may be remnants of collapsed trough wall sediment, although it may also have blown in from elsewhere. The three-way trough intersections prevalent on the upper surface are often characteristic of more evolved terrestrial polygon fields [Sletten et al., 2003]. These polygons thus do not appear very fresh and the network may be relatively old. On Earth, permafrost thermal contraction cracks evolve slowly, opening a few centimeters each year, according to Lachenbruch [1962]. Applying this terrestrial rate to the large, upper surface Martian polygons, the latter could have formed over a few hundred years. However, lower deposition rates on Mars, and hence less infilling of cracks by sediment, could allow cracks to close more completely each year, lengthening the required formation time.

\subsubsection{Scallop Polygons}

[25] The rectangular shape and orientation of polygons at the top of scallop scarps is likely to arise from a gravity stress field induced by the slope. Such control effects have been described on Earth [Mackay, 1995]. Similarly, Mangold [2005] attributes similar rectangular polygons on the inside part of Martian crater walls to this effect of slope. These crater polygons are concentric and parallel to the slope and often change to random orthogonal systems further down the slope,

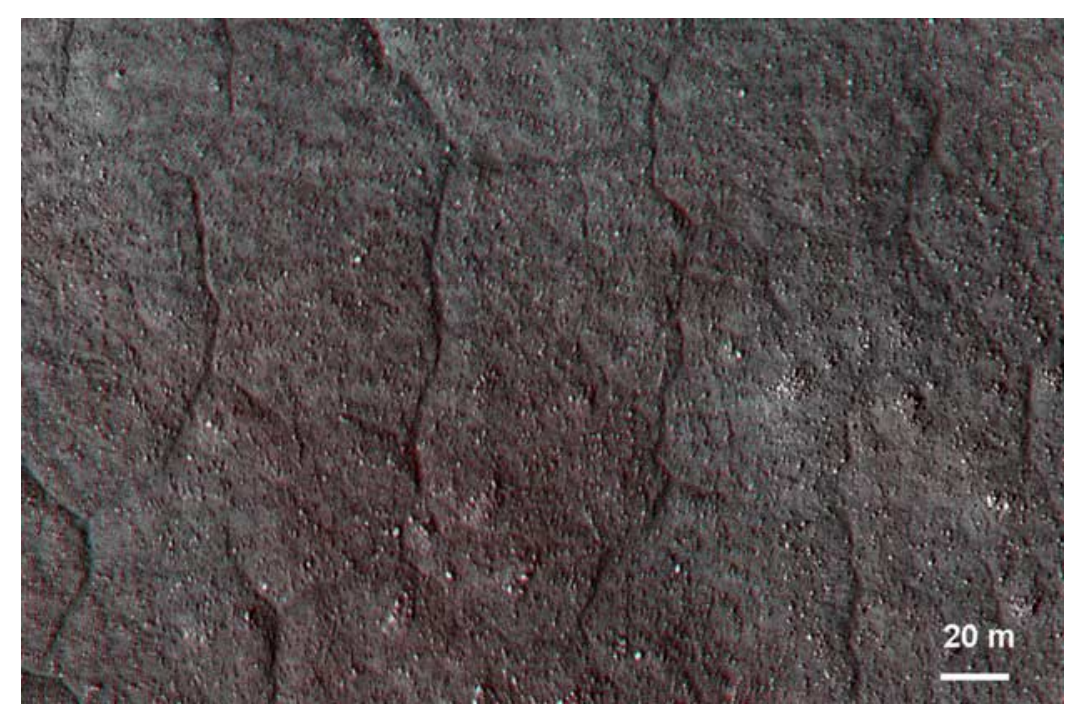

Figure 11. Large upper surface polygons and rocks. These polygons are about $50 \mathrm{~m}$ wide, with globally flat or slightly raised centers and large troughs ( 2 to $4 \mathrm{~m}$ wide). They are covered by rocks about up to $2 \mathrm{~m}$ large (anaglyph made from the HiRISE stereo pair PSP_1938_2265/PSP_2439_2265; 46.03 ${ }^{\circ} \mathrm{N}$, $92.1005^{\circ} \mathrm{E}$ ). 


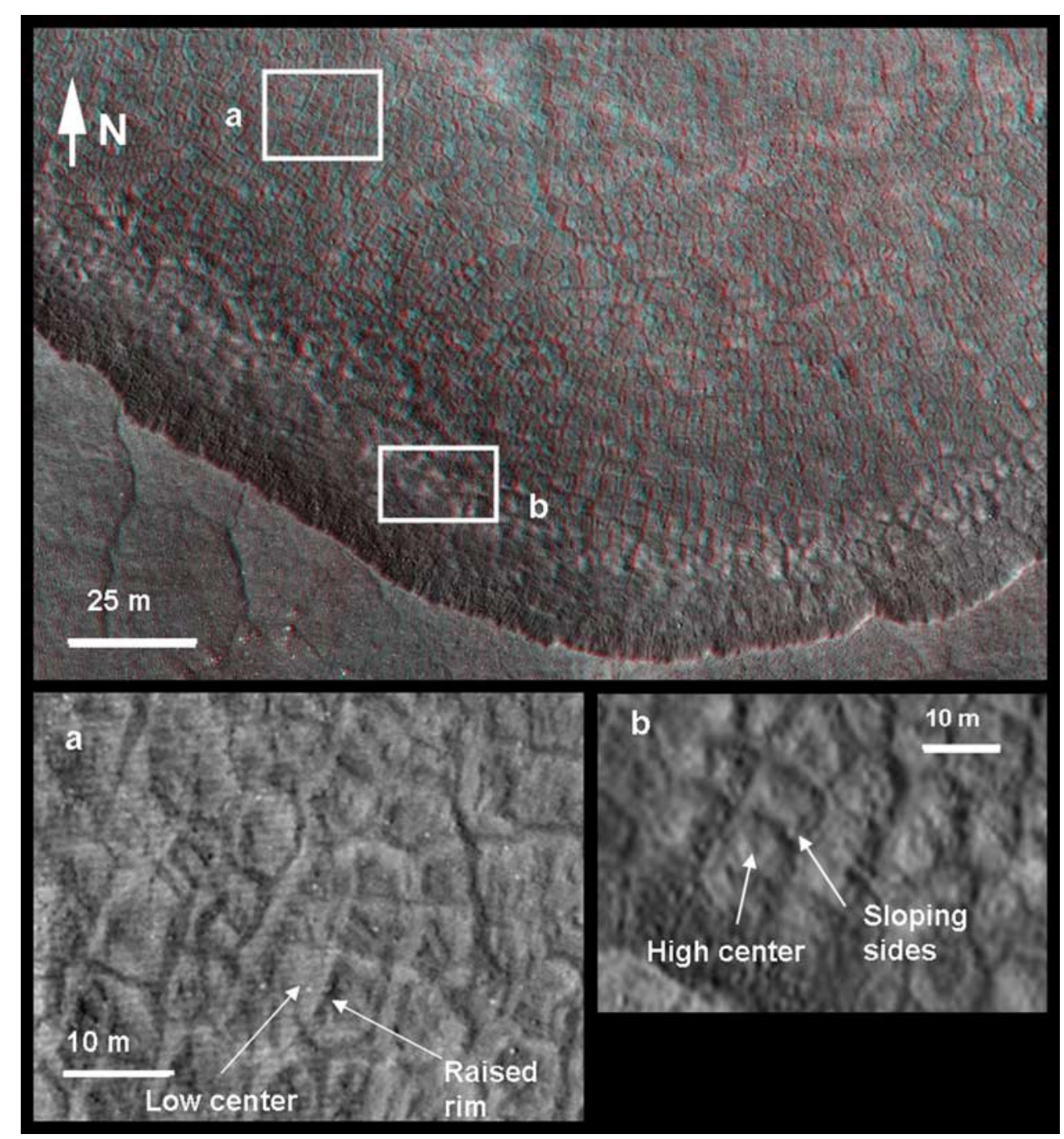

Figure 12. (a) Small low-centered polygons. The interridges terrain typically displays polygons with low center and raised rims, reminiscent of ice wedge polygons on Earth. This morphology may result from the fact that the ice table may be close to the surface in the lower parts of the scallops. (b) Small high-centered polygons. The polygons that form over the ridges have high center and convex sides, similar to Earth sublimation polygons. They may be older polygons than the low-centered polygons, or they have been more eroded because of a more exposed position or because of a different type of substrate (anaglyph made from the HiRISE stereo pair PSP_1938_2265/PSP_2439_2265; 46.031 $\left.{ }^{\circ} \mathrm{N}, 92.1005^{\circ} \mathrm{E}\right)$.

just as we observe in scallops. On the scallop floor, the lowcentered and raised rim morphology of polygons located inbetween the ridges is reminiscent of relatively unmodified ice wedge or sand wedge polygons. Models show that repeated freezing and thawing of an active layer above permafrost is very unlikely on Mars given current atmospheric conditions [e.g., Mutch et al., 1976; Carr, 1996; Hecht, 2002; Sears et al., 2005]. The cold and dry Martian conditions have their closest terrestrial analogs in polar deserts such as the McMurdo Dry Valleys in Antarctica and are more conducive to the formation of sand wedge polygons. The high centers and more gently sloping sides of the polygons on the internal ridges indicate that, while they may have formed from a similar mechanism, they have likely experienced greater erosion than their lower neighbors. Possible causes for these currently differing appearances include greater sublimation of interstitial ice, exposure to wind, and/or time since activity of the ridge polygons, greater sediment trapping in troughs or closer proximity to thermal stresses of the interridge polygons, and inherent differences in the substrate. In general, polygons associated with scallops appear relatively younger than their larger, upper surface counterparts owing to narrower trough widths and more pristine appearance of some trough walls.

[26] The presence of the smallest scallop interior polygons closest to the steep scarp, their gradually increasing size toward the center over the rising scallop floor, and their general absence on the gentle rise presents a paradox. At the latitude of Utopia and at the current obliquity, pole-facing slopes receive less insolation than flat or equator-facing surfaces. Thus, the amplitude of ground temperature cycles due to solar heating should be greater further from the slope and shadowing of the scarp. Temperature changes are one of the main causes of thermal stress that results in polygon 


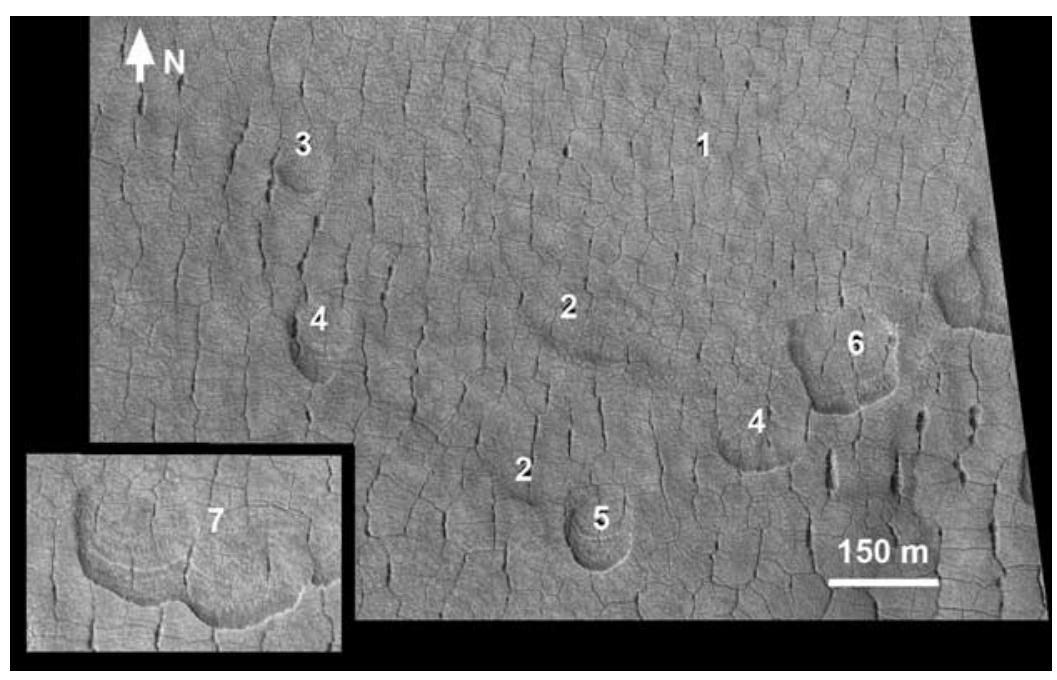

Figure 13. Scallop morphologies in relation to their sizes. Stage 1 consists of areas of bumpy terrain, with shallow, north facing scarps (as in stage 2). Stages 3 and 4 consist of shallow depression without floor ridges or small polygon network on the scarp. The large polygon network on the upper surface typically overlays these small and shallow scallops. Stages 5 and 6 consist of larger scallops (from $100 \mathrm{~m}$ diameter) with longer scarps overlooking a more extended, deeper depression, where several ridges may be observed. Small polygon network are observed on the scarp. Stage 7 consists of coalescing scallops (both images are parts of HiRISE image PSP_001582_2245; $44.356^{\circ} \mathrm{N}, 86.434^{\circ} \mathrm{E}$, illumination is from the bottom left).

formation, and in similar materials generally, the higher the stresses, the smaller the polygons [Lachenbruch, 1962]. This paradox is addressed and explained below.

\subsection{Relationships Between Scallops, Polygons, and Ridges}

[27] We observe relationships between the polygon network, the ridges and the bounding slopes of the scallops that may reflect the relative ages of these features and yield clues to their formation. The large network is incised continuously over the upper surface and down the gentle rise of scallops. Following the topography of this rise seems to suggest that the network is more recent than the scallops. However, the large network troughs are thinner and less distinct on the gentle scallop rise. This abrupt change in character of the upper surface troughs extending onto the rise could be caused by downward erosion of the rise through a preexisting polygonized surface during scallop formation. Indeed, if we consider that troughs cut into the preexisting surface narrowed with depth (as the troughs of the upper surface network appear to do), then the progressive downward removal of material from this surface during rise formation would lead to erosion of the top, wider, part of the troughs, resulting in apparently thinner troughs on the new, lower sloping surface (Figure 16). On the scarp side of most scallops, the large troughs of the upper surface network are typically interrupted by the scarp and do not intersect orthogonally with the scarp. Orthogonal intersections would be expected if the upper surface troughs had formed after the scarp, because of the control exerted by the topographic break on near-surface stress conditions, as observed in Earth periglacial environments [French, 2007]. This clearly argues for the scarps being a more recent feature than the large, upper surface polygon troughs, although concurrent evolution remains possible.

[28] Since small, interior polygon networks are only observed in scallops with relatively high and steep scarps, they must be more recent than the initiation of scallop formation and the beginnings of scarp development; they may first appear when a certain stage of scarp development is reached and coevolve thereafter. The formation of these polygons within scallops may be synchronous with that of the interior nested ridges, as both types of features appear in scallops over a certain size threshold (Figure 13, stage 5). The ridges could be constructional or erosional. Since there is no color difference between the ridges and the surrounding terrain, there is

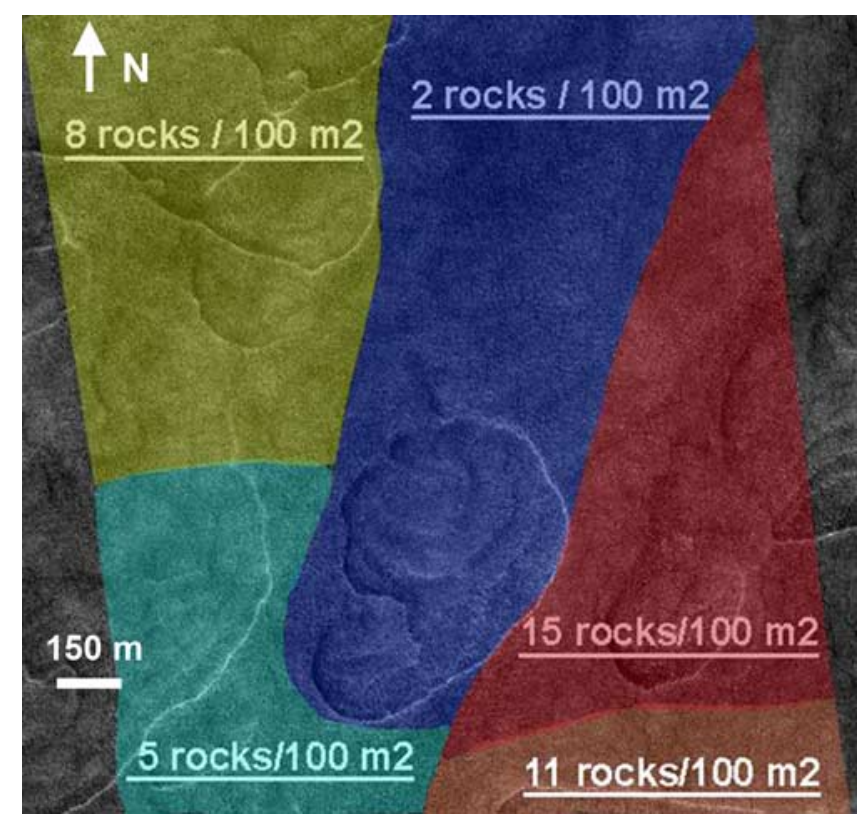

Figure 14. Rock density map. Illumination is from bottom left. North is at the top (HiRISE image PSP_001938_2265; $\left.46.031^{\circ} \mathrm{N}, 92.1005^{\circ} \mathrm{E}\right)$. 


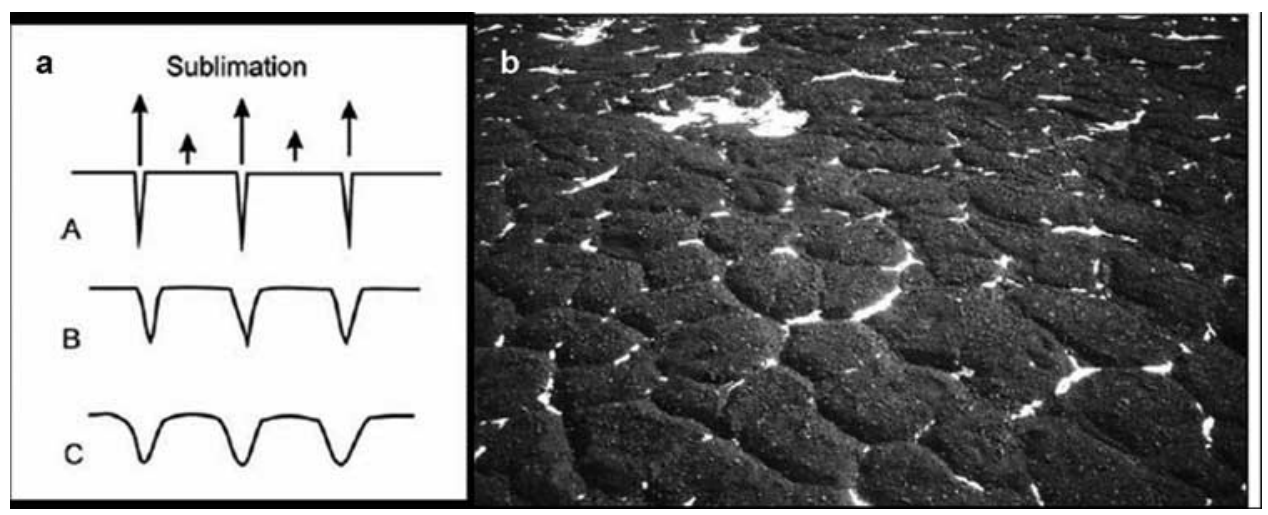

Figure 15. Sublimation polygons. (a) Formation process. Sublimation of ground ice within the cracks causes softening of the dust material and progressive collapse and enlargement of the troughs, forming high center polygons (from Mangold [2005], with permission from Elsevier). (b) Example of sublimation polygons in Beacon Valley on Earth. These polygons have raised centers and deep and large troughs [from Marchant et al., 2002].

no evidence that protruding subsurface layers with different material composition account for them. Considering their curvilinear structure, almost always parallel to the scarp, they should be related to or influenced by the scarp. They most likely mark previous locations of a progressively moving scarp, thus implying episodic stages of scarp erosion. Other geomorphological features, such as promontories and buttes standing above the scallop floor near the scarp edge closely

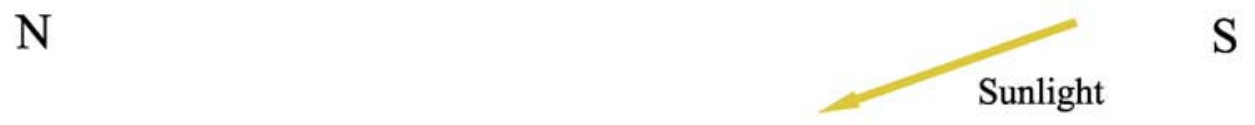

a
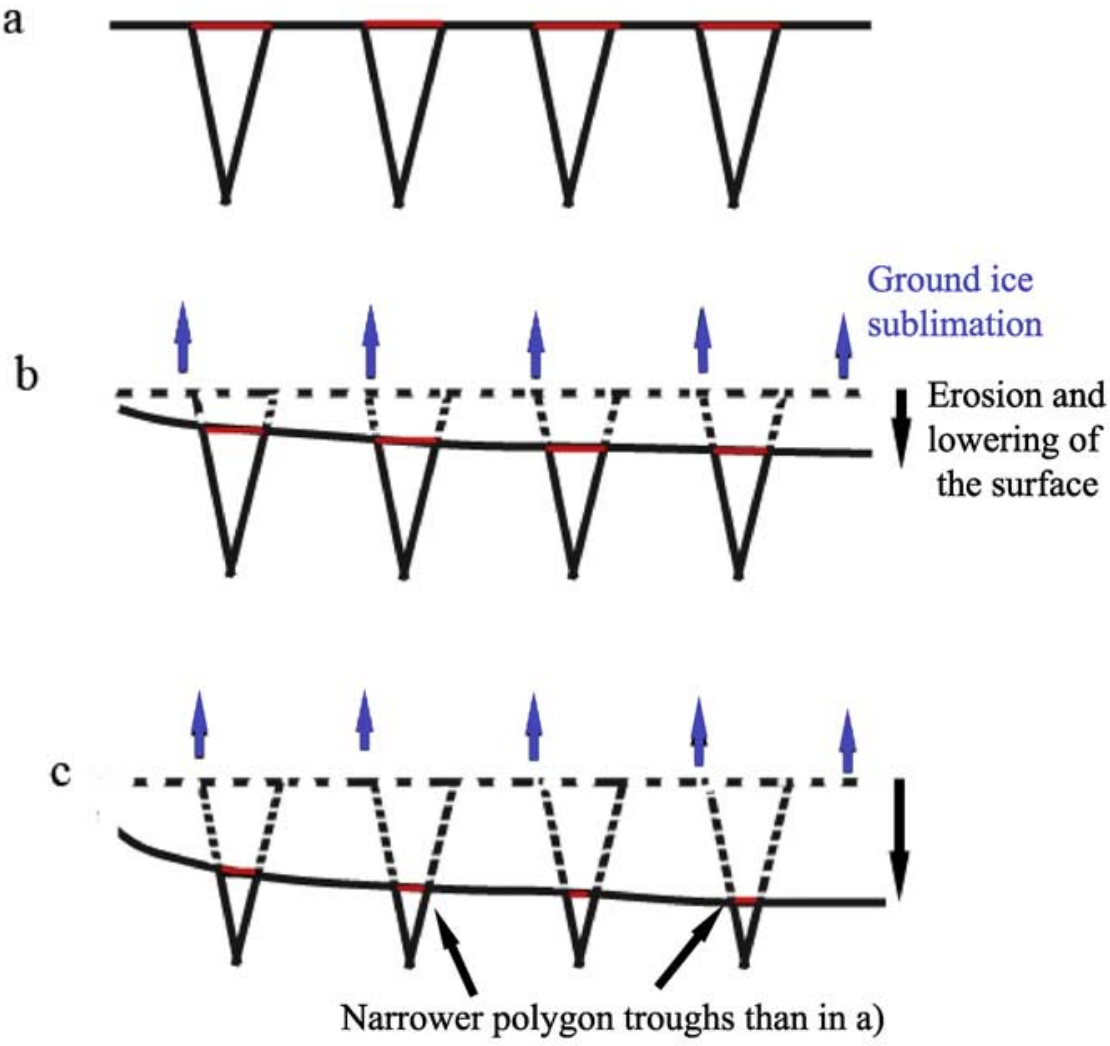

Figure 16. Downward erosion of a preexisting polygonized surface during scallop formation. Since the troughs that cut into the preexisting surface (Figure 16a) narrow with depth, then the progressive downward removal of material from this surface (Figure 16b) leads to erosion of the top, wider part of the troughs, resulting in apparently thinner troughs on the new, lower surface (Figure 16c). 


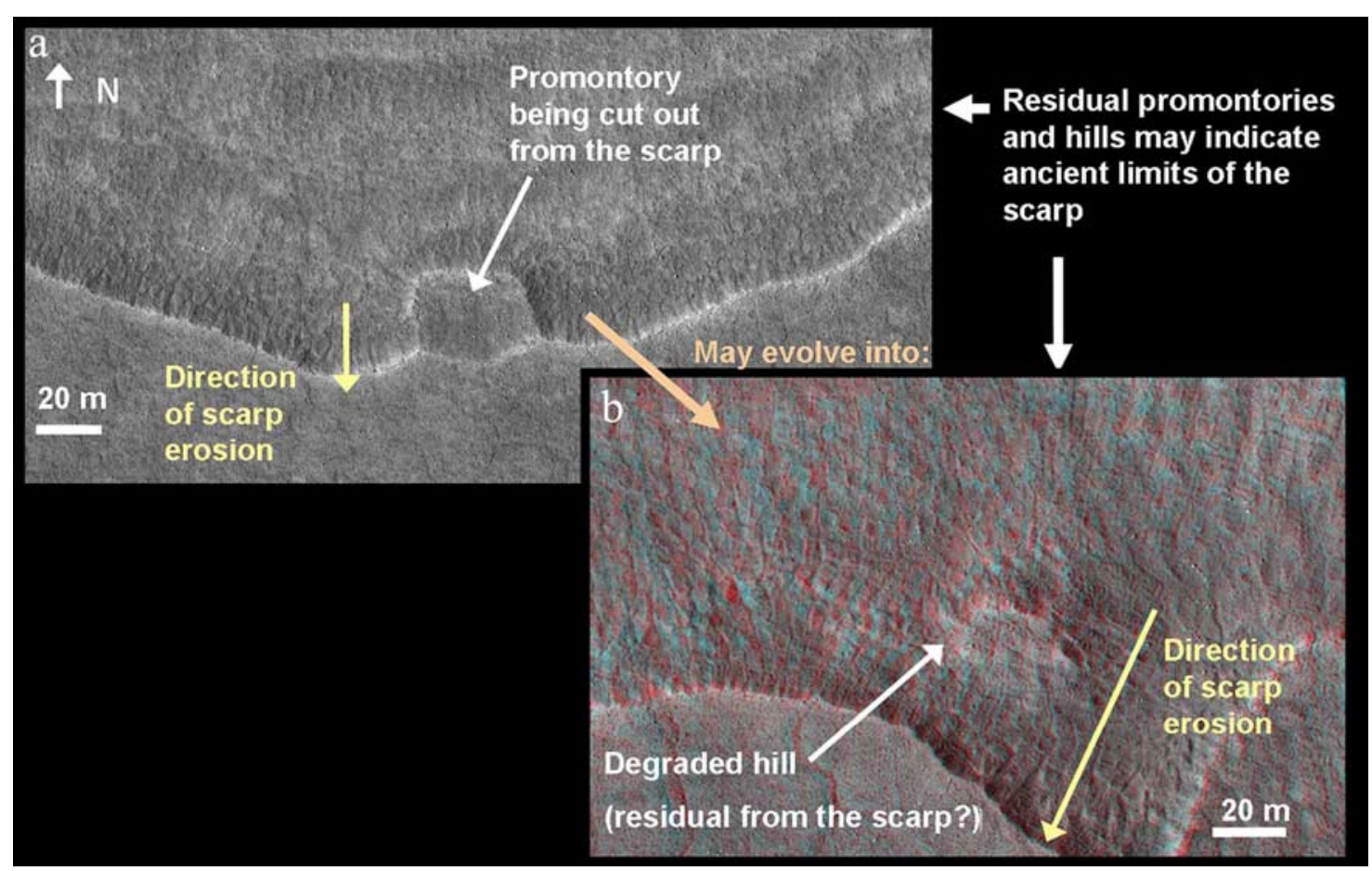

Figure 17. Promontory and residual butte. (a) Residual promontory left after retreat of the scarp. (b) This promontory may evolve into a residual butte subsequently degraded by polygonal cracks. These residual promontories and buttes may indicate ancient limits of the scarp (HiRISE image PSP_2439_2265 and anaglyphs PSP_001938_2265/PSP_0024398_2265, $\left.46.031^{\circ} \mathrm{N}, 92.1005^{\circ} \mathrm{E}\right)$.

and strongly support this interpretation by suggesting that the scarp has retreated, leaving remnants behind (Figure 17).

[29] As mentioned, development of the small polygons is likely associated with and dependent on the development of the scarp. Since scallops formed after the large polygons in the upper surface, larger scallops are deeper than small ones, and high remnants are occasionally left just interior to the scarp, it is evident that the scarp reaches deeper and erodes headward and the floor descends as the scallop evolves. The initiation and formation of the small polygons, by thermal contraction of ice-rich ground, may be triggered and sustained by thermal and ground ice conditions that are (1) achieved at some point in scallop evolution and maintained and (2) particular to the environment of the scarp slope and nearby scallop floor. The amount of insolation, influenced by the slope and aspect of the scarp, and the depth to the ice table, which decreases relative to the depth-to-ice from the original level of the upper surface, are two important factors that are local to the scarp area and evolve with scarp development. The simplest explanation for the absence of small polygons on the upper surface and their appearance within sufficiently deep depressions is that only in such depressions is the surface close enough to the ice table for the thermal stresses induced by penetration of the thermal wave to result in polygon formation. In turn, these observations suggest that the depth to the ice table in this region is on the scale of the height of the scarp when the small interior polygons begin to form, or $\sim 3 \mathrm{~m}$, as estimated from the HiRISE DEM.

[30] As mentioned above, the slopes of the pole-facing scarp receive less insolation than surfaces further to the interior, and should consequently remain colder. These generally lower temperatures should permit ground ice a greater stability nearer to the surface. This relative, heightened stability would be maximized on the inner scarp surface and on the scallop floor in immediate proximity to the scarp, decreasing toward the interior. This may be the key to explaining the apparent insolation paradox. Despite a relatively lower amplitude of temperature variation, pole-facing surfaces may experience greater thermal stress because of greater near-surface ice content [Mellon, 1997, also personal communication, 2007]. The existence, distribution, and size variation of the small polygons is consistent with this hypothesis. Further from the scarp, the polygons are progressively larger due, according to this hypothesis, to a deeper ice table resulting from higher insolation (Figure 18).

\subsection{Discussion on Scallop Formation Processes}

[31] There are several possible processes that could have contributed to formation of scalloped depressions, either known from Earth periglacial processes, such as thermokarst lake formation [e.g., Soare et al., 2008], slumping [French, 2007], or previously proposed for Mars, such as ground ice sublimation [Plescia, 2003; Morgenstern et al., 2007; Lefort, 2008]. There is reason to think that aeolian processes, such as dust devils, must contribute to associated erosion processes generally since the dust fraction of the ice-rich material missing from these depressions must have been transported away by some mechanism. However, the complex nature of these features is likely to involve other processes in their initiation and evolution. In this section, we consider these processes and determine which of them is the most likely.

\subsubsection{Ground Ice Sublimation}

[32] The presence of current ground ice in Utopia Planitia is suggested by the GRS observations and ice stability 


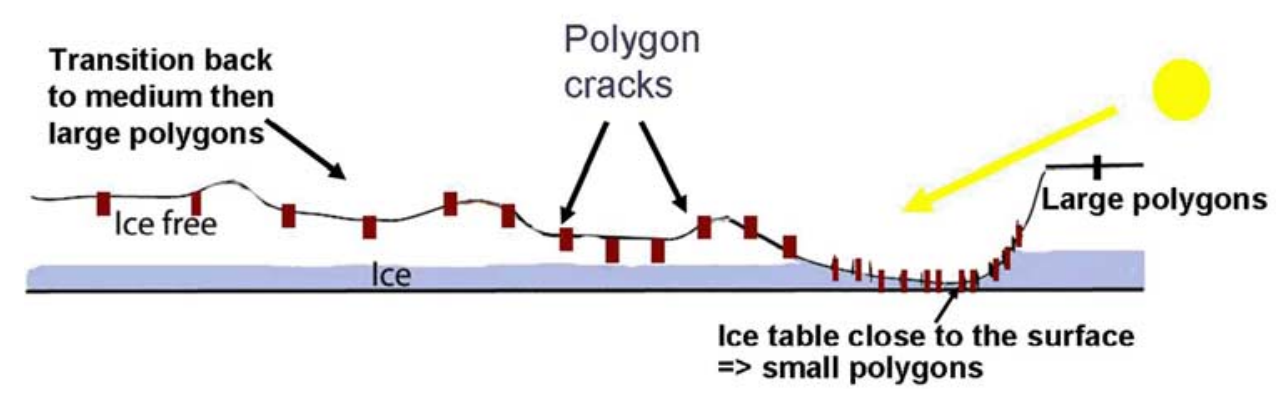

Figure 18. Polygon formation in relation to the scallop scarp.

models. The presence of polygons reinforces this interpretation, although they do not unambiguously prove the presence of ice. The typical north-south asymmetrical morphology of scallops, their latitude-dependent distribution [Milliken and Mustard, 2003] and the apparent absence of slope or altitude dependence in their distribution, suggests that the formation process is controlled by climatic and insolation factors rather than terrain-related factors. These findings are consistent with theory, in that ground ice is believed to be stable in the current climate from about $45-55^{\circ}$ latitudes and poleward [e.g., Mellon and Jakosky, 1993]. This places the scallops just at the limit of the unstable zone, where ground ice sublimation may still be occurring as ice distribution lags in its adjustment to climate. Relatively low thermal inertia values are consistent with a dry regolith with no ice present in the surface material. This is also consistent with theory, considering that ice directly exposed at the surface should not be stable at these latitudes [e.g., Mellon and Jakosky, 1993]. Hence, both observations and theory suggest that ground ice may be present under a thin layer of desiccated materials protecting it from fast sublimation. Water from this "ice table," or subsurface level below which ice is present, may be sublimating slowly through the insulating layer. Surface irregularities, like bumps, cracks or small depressions may contribute to increase ground ice sublimation rates by thinning the desiccated layer or even exposing the underground ice-rich layer.

[33] With the above considerations, we propose a model in which insolation on the scallops' equator-facing slopes enhances ice sublimation. In a feedback process, this erosion produces a larger equator-facing surface for insolation to act upon. Specifically, this erosion process comprises the removal of ice and its effectiveness as a cementing agent, the resulting softening of the slope, and degradation of preexisting surface features such as troughs of the large, upper surface polygon network. The scallop asymmetry is reminiscent of asymmetrical valleys in the periglacial regions of Earth. In midlatitude North America these valleys commonly have a steeper slope facing the north/NE and a gentler slope facing the south/SW owing to differential insolation and freezethaw processes operating on exposed south facing slopes [Ollier and Thomasson, 1957; French, 2007]. Plescia [2003] invokes ice sublimation to explain the formation of scalloped depressions in Peneus and Amphitrites Patera in the southern hemisphere. These depressions have a similar morphology to those in Utopia Planitia, with steep scarps facing south instead of north.
[34] As a by-product of sublimation we expect an accumulation of desiccated material, at a rate depending on the ice/material ratio. Without additional erosion processes, such desiccated material would eventually build up to insulate the underlying ice-rich mantle from insolation and inhibit the rate of scallop formation. Following observations of dust devil tracks on MOC and HiRISE images and other evidence of Martian wind storms at these latitudes [Smith et al., 2006], it seems likely that wind deflation could remove part of the desiccated material accumulated in scalloped depressions. It is unlikely that the excavated volume of the scallop depression corresponds directly to the volume of sublimated ice, which would imply an ice fraction well in excess of that estimated for this mantle. Evidence of aeolian erosion may be observed in the form of dunes, which may form from the gathering of material removed from the scallops.

[35] The small elongated pits appearing sometimes within polygonal cracks have been proposed as a potential starting point for scallop development [Morgenstern et al., 2007]. However, scallops are generally sparse in areas where these pit chains are observed and neither do we observe evolution intermediates of these pits into scalloped depressions. Such pits may be located both inside and outside of scallops and scallop scarps sometimes appear to have cut through them. Tellingly, several areas of scalloped terrains do not display these pits. It therefore seems that, while both may involve sublimation processes, the elongated pits and the scalloped depressions are independent features [Lefort, 2008].

[36] So how does sublimation initiate a scallop? On the basis of observation of bump- and depression-covered terrain where small scarps appear in various stages of development (Figure 13), we propose a model for scallop and polygon evolution. The process starts on initially slight hummocks or depressions with relatively heightened near-surface temperatures on their equator-facing slopes, leading in turn to enhanced sublimation of ground ice on these equator-facing slopes (Figure 13, stages 1 and 2). This enhanced sublimation leads to an asymmetric scallop-shaped depression with a progressively retreating gentle rise and a steeper, for the moment stationary, pole-facing scarp (Figure 13, stages 3). Over time this process deepens and extends the scallop, mainly by erosion of the equator-facing rise and accompanying alteration of the superposed large polygon troughs, as described in section 3.3 (e.g., Figure 13, stages 4 and 5). At some point the scallop becomes large and deep enough to initiate (1) formation of small polygons on and near the scarp due to the decreasing depth to the ice table, as described in 
section 3.3 (Figure 13, stages 5 and 6) and (2) episodic retreats of the scarp, which leave behind internal ridges, discussed further below (Figure 13, stages 4-6). Remnants of buttes detached from the retreating scarp may be left standing above some scallop floors (Figure 17). Headward erosion of the scarp into the upper surface cuts and removes large polygon troughs (Figure 13, stage 6). This evolution explains why large, upper surface polygon troughs are not often orthogonal to the scarp, being relatively older features. With retreat of the scarp extending also laterally toward the east and west, the cupping of the central depression gives the characteristic "scallop" shape (Figure 13). Finally, aging scallop neighbors can coalesce (Figure 13, stage 7) occasionally leaving thin, ridged remnants among them.

[37] While the first step of this model explains the asymmetry of the scallops, the gentleness of the equator-facing rise and the erosion of large polygon troughs on the gentle rise, we have not yet explained the headward erosion of the polefacing scarp or ridge formation. We currently propose two possible explanations, although none of them is fully satisfactory. One involves small localized landslides on the scarp; the other slumping events occurring at high obliquity periods. Being pole-facing, the scarp should receive less insolation and, therefore, be less prone to sublimation, more ice-rich, and more stable relative to the gentle rise. We refer here to the explanation presented above that the formation of the small polygon network is due to relatively high ice concentrations at the scarp and deepest parts of the scallop floor. Deepening of the scallop by deflation of the gentle rise brings the floor of the scallop closer to the ground ice. This not only leads to formation of relatively small, highly stressed polygons, but also effectively brings the ice closer to the atmosphere, leading to an increase in sublimation rate near the scarp. The density of polygonal crack formation in that area would also render the scarp more fragile by reducing its coherence. After the ice in the sediment is sublimated, the sediment is no longer cemented and may easily fall down the scallop scarp, in episodic, very small landslides, hence leading to scarp retreat. We do not observe such landslides but loose material could have been transported by wind since the last occurrence of scarp retreat. Loose material could also be present, but unseen, being below the current threshold of image resolution.

[38] The presence of the interior ridges suggests another possible process for scarp retreat. The morphology of these interior ridges, their continuous, scarp-parallel expression, and their asymmetric profile are all features reminiscent of thaw slump in Earth periglacial environments. Such slumping occurs when the entire edge of the scarp loses integrity owing to thawing of ice-rich permafrost and moves downslope together. The detached material generally takes a lobate shape that resembles that of the ridges [French, 2007]. The fact that thawing is currently considered unlikely at these latitudes [e.g., Mutch et al., 1976; Carr, 1996] combined with the fact that scallop scarps are mostly pole-facing and, therefore, receive minimal insolation, does not fit with this hypothesis. However, calculations with a one-dimensional global climate model show that under higher obliquity conditions $\left(\geq \sim 45^{\circ}\right)$ (1) middle- to high-latitude, pole-facing slopes actually achieve higher day-averaged summer temperatures than equator-facing slopes, (2) on these same slopes, the annual mean temperature is lower, and (3) atmospheric water is expected to be relatively abundant [Costard et al., 2002]. Thus, at high obliquity, the pole-facing, steep scarps will be the site both of highest ice stability and likely deposition during the winter, and of relatively fast sublimation and potential thawing in the summer. It may be during these periods that the steep scarp sheds material more rapidly. If removal of slumped or mass-wasted material by the wind is not able to keep up with this increased rate of scarp erosion, a ridge of the material is left behind. We find that this model explains the morphology and distribution of the ridges as markers of episodic heightened activity at obliquities $\geq \sim 45^{\circ}$. If each ridge corresponds to a different period of high obliquity, the typical presence of two or three interior ridges suggests that formation of the larger scallops has occurred over several obliquity cycles.

[39] In summary, our model requires alternating high and low obliquity to get the alternating sublimation pattern. Sublimation during lower obliquity periods leads to the gradual formation of the equator-facing rise, while sublimation and possible thawing during high obliquity leads to mass wasting and/or slumping and the retreat of the pole-facing scarp. The small polygons associated with the steep scarp could develop in either or both obliquity regimes: at low obliquity with low temperature values and amplitudes but close to the subsurface ground ice (as described in section 3.3), and at high obliquity with very high temperature amplitudes and the possibility of ice regeneration in the near surface and a potential freeze-thaw cycle. Likewise, retreat of the steep scarp probably continues at low obliquity but perhaps at a slower rate than at high obliquity. This model explains the main features of scalloped depressions, including the asymmetry in slope and aspect, the polygons, and the ridges.

[40] We have not estimated quantitatively which specific configurations of obliquity may be satisfactory in producing the observed geology within our model. However, it is clear from orbital models that variation of obliquity occurs over a range vastly greater than that of Earth, and also that alternation between relatively high and low values may be expected over relatively short geologic periods [Laskar et al., 2004]. The deposition, removal, and multiple layers of mid latitude mantles and DMT likewise argue for a cyclical influence on their evolution [e.g., Head et al., 2005]. Furthermore, scallop asymmetry requires the erosional effects of the obliquity variations which dominated scallop formation to have been different in nature and/or magnitude on the opposing scallop slopes. This is possible since the obliquity is symmetric about the equator, not about the scallops, and since Mars does not spend the same amount of time at high and low obliquity. This would lead to illumination asymmetries over the scallops, which would in turn lead to morphological asymmetries. Moreover, sublimation depends on illumination, which is not only dependant on obliquity, but also on other parameters, such as heliocentric distance. Therefore, illumination conditions are very unlikely to be similar at each obliquity and scallops are more likely to be asymmetrical than symmetrical.

[41] Thus, our study provides qualitative constraints on the obliquity configurations necessary for scallop formation, which in turn could help date scallop formation if it occurred within the extent of the known orbital record. While obliquity models of Mars are relatively precise over the last 10 to $20 \mathrm{Ma}$ [Laskar et al., 2004], what is largely unknown is how orbital variations translate into geological and volatile activity, 
which cycles are responsible for which emplacement, removal, and landscape evolution processes. Matching our scallop evolution model with quantitative predictions of illumination, climate, and near-surface thermal behavior at given orbital configurations may provide a small piece of evidence toward understanding the links between orbital variations and surface activity.

\subsubsection{Thermokarst Lakes}

[42] The possibility that the scalloped depressions were caused by ancient thermokarst lakes has been proposed by several authors [Costard and Kargel, 1995; Soare et al., 2008; Wan Bun Tseung and Soare, 2006]. A thermokarst lake is formed by subsidence and subsequent settling of the ground resulting from the thawing of ice in the active layer above thick permafrost. Water fills the resulting depression, forming a lake. This process occurs in frozen, fine-grained sediments in which the volume of ice present exceeds the normal porosity volume if the sediment were ice-free [Carson and Hussey, 1962]. Once formed, the water of a thermokarst lake acts as a thermal battery. This results in progressive annual thawing and melting of the underlying permafrost. This progression, combined with wave erosion at the banks, causes further collapse, slumping, caving and erosion of the banks, enlarging the lake [French, 2007].

[43] This type of lake shares several characteristic with the scallops of Utopia Planitia. Thermokarst lakes are typically rimless, steep-sided, relatively flat-floored, shallow (less than $25 \mathrm{~m}$ deep), roughly circular, scalloped or lobate and can be up to $1-2 \mathrm{~km}$ in diameter. Moreover, ridges within the scallops could have their analog in lacustrine terraces, representing different stages of lake evolution. Terrestrial thermokarst lakes also can coalesce. Accordingly, large coalescent scallops dissected by small interior scallops could represent successive episodes of thermokarst formation. Thermokarst lakes in Utopia Planitia would require thawing of an ice-rich permafrost and the retention of meltwater in the resulting surface depression. As mentioned, most models show that extensive melting is impossible at these latitudes under current climate conditions [e.g., Mutch et al., 1976; Carr, 1996]. Studies that suggest near-surface melting is possible at differing orbital configurations do so for limited geographic and topographic settings, partial times of the year, and provide for small amounts of water [e.g., Costard et al., 2002; Hecht, 2002]. The volumes suggested by the scalloped depressions would be exceedingly difficult to produce, and would be impossible to maintain as a liquid through the year. An alternative could be melting via an internal source of heat. Anomalous gravity evidence led De Pablo and Komatsu [2007] to propose the geologically recent presence of a magmatic chamber under the surface of the Utopia Basin that could create hydrothermal circulation, although further supporting evidence for this has yet to be established. The pattern would have to be such that conduits heated relatively localized areas of the surface on the scale of hundreds of meters, yet did so over an area of $\sim 2.5$ million $\mathrm{km}^{2}$ (estimated area of Utopia Planitia covered by scallops), leaving areas of permafrost in between intact. More problematic is the consistent north-south asymmetry of the scallops. Moreover, floors of the scallops are tilted and occur at different altitudes, both aspects that are inconsistent with coalescing lakes. The peaked profile of the ridges (Figures 8 and 9) is also different from that of typical Earth lacustrine terraces, which generally have a flat, stepped profile. Also, there is little further evidence of the presence of water within the scallops (e.g., deltas or drainage patterns) aside from the small polygon network. Because of these different considerations, we consider the origin of the scallops as thermokarst lakes to be unlikely.

\section{Implication of the Rock Distribution in Utopia Planitia}

[44] The origin of the boulders, covering not only Utopia Planitia but also large parts of the northern plains, is still subject to debate. Current proposed hypotheses include crater ejecta, ancient ejecta blankets, deposits of the outflows from the Elysium channels or by continental glaciers, and induration of thin material [McEwen et al., 2007b]. We have observed that some of the boulders in our study area are concentrated on the rims of craters about $300 \mathrm{~m}$ diameter and are thus most likely ejecta. Considering the relatively small size of these craters, the impact should not have excavated very deeply ( $\sim 1 / 10$ crater transient diameter) [see Melosh, 1989], suggesting that these rocks come from a relatively shallow unit. Apart from the boulders concentrated around craters, most of the boulders are randomly scattered over the surface, as the global rock density is similar inside and outside of the scallops (Figure 14). Importantly, this means that the formation of scallops by erosion and removal of nearsurface material did not serve to significantly increase the concentration of boulders as coarse lag material. In turn, this could be interpreted to demonstrate that the upper $25 \mathrm{~m}$ of the ground, corresponding to the average scallop depth, is generally poor in boulders. In fact, it is consistent with the concentration of boulders solely on the surface and not within it. In this regard, boulders we see within scallops simply correspond to those that were located on the upper surface previous to scallop formation and were lowered with the surface in the process. This interpretation is supported by the relatively few embedded rocks observed within mantle outcrops in the Northern Plains [Searls et al., 2007]. These observations support the theory that the midlatitude mantle is made essentially of a mixture of ice and fine material, with the boulders superposed later. Alternatively, the ice sublimation at depth may have led to a lowering of the surface layer, thus preserving the average boulder distribution, and the starting material was not necessarily an air fall mantle.

\section{Conclusions}

[45] Under HIRISE scrutiny, Utopia Planitia displays an assemblage of periglacial features which appear more complex than suggested by MOC images. Interior detail of scallops reveals a clearly oriented morphology with steep pole-facing scarps, gentle equator-facing rises, and interior curvilinear ridges. Some of the most striking new features are the different types of polygons, large on the upper surface, small on and along the scarp, and intermediate on the gentle rise of scallops. We observe a related evolution between the scallops, ridges and polygons which implies that their formation processes are interrelated. While the large polygons formed either before or in parallel with scallop development, the small polygon network is clearly linked to mature scallop development. These different polygon forms and their distribution probably reflect asymmetric depths of the ice table and 
ice concentration. The midlatitude concentration of scallops, their asymmetry and independence to altitude suggests that scallop formation is likely controlled by climatic and insolation processes involving ground and near-surface ice sublimation processes, possibly including by localized thawing and slumping events. While we do not see any sign yet of current activity, it is possible that sublimation is ongoing, especially in scallop scarps, though evolution must be at a very slow rate.

[46] Acknowledgments. We thank the people at the University of Arizona, the Jet Propulsion Laboratory, Ball Aerospace, and Lockheed Martin that built and operate the HiRISE camera. We also thank the people of the HiRISE Operations Center (HiROC) at the University of Arizona for acquiring and processing the HiRISE images used for this study. This work was supported by the Swiss National Science Foundation.

\section{References}

Allen, C. C., and L. C. Kanner (2007), Present-day exposures of water ice in the northern Mid-latitudes of Mars, Lunar Planet. Sci., XXXVIII, Abstract 1174.

Boynton, W. V., et al. (2002), Distribution of hydrogen in the near surface of Mars: Evidence for subsurface ice deposits, Science, 297(5578), $81-$ 85, doi:10.1126/science. 1073722 .

Carr, M. H. (1996), Water on Mars, 248 pp., Oxford Univ. Press, New York.

Carson, C. E., and K. M. Hussey (1962), The oriented lakes of arctic Alaska, J. Geol., 70, 417-439.

Chamberlain, M. A., and W. V. Boynton (2007), Response of Martian ground ice to orbit-induced climate change, J. Geophys. Res., 112, E06009, doi:10.1029/2006JE002801.

Chapman, M. G. (1994), Evidence, age, and thickness of a frozen paleolake in Utopia Planitia, Mars, Icarus, 109, 393-406, doi:10.1006/icar. 1994.1102.

Christensen, P., et al. (1992), Thermal Emission Spectrometer Experiment: Mars Observer Mission, J. Geophys. Res., 97(E5), 7719-7734.

Costard, F. M., and J. S. Kargel (1995), Outwash plains and thermokarst on Mars, Icarus, 114, 93-112, doi:10.1006/icar.1995.1046.

Costard, F., F. Forget, N. Mangold, and J. P. Peulvast (2002), Formation of recent Martian debris flows by melting of near-surface ground ice at high obliquity, Science, 295(5552), 110-113, doi:10.1126/science.1066698.

De Pablo, M. A., and G. Komatsu (2007), Pingo fields in the Utopia Basin, Mars: Geological and climatic implications, Lunar Planet. Sci., XXXVIII, Abstract 1338 .

Dundas, C. M., M. T. Mellon, A. S. McEwen, A. Lefort, L. P. Keszthelyi, and N. Thomas (2008), HiRISE observations of fractured mounds: Possible Martian pingos, Geophys. Res. Lett., 35, L04201, doi:10.1029/ 2007GL031798.

Feldman, W. C., et al. (2004), Global distribution of near-surface hydrogen on Mars, J. Geophys. Res., 109, E09006, doi:10.1029/2003JE002160.

Fergason, R. L., P. R. Christensen, and H. H. Kieffer (2006), High-resolution thermal inertia derived from the Thermal Emission Imaging System (THEMIS): Thermal model and applications, J. Geophys. Res., 111, E12004, doi:10.1029/2006JE002735.

French, H. M. (2007), The Periglacial Environment, 3rd ed., 458 pp., John Wiley, Chichester, U. K.

Head, J. W., M. A. Kreslavsky, and S. Pratt (2001), Northern lowlands on Mars: Evidence for widespread volcanic flooding and tectonic deformation in the Early Hesperian, Lunar Planet. Sci., XXXII, Abstract 1063.

Head, J. W., J. F. Mustard, M. A. Kreslavsky, and R. E. Milliken (2003), Recent ice ages on Mars, Nature, 426, 797-802, doi:10.1038/nature02114.

Head, J. W., et al. (2005), Tropical to mid-latitude snow and ice accumulation, flow and glaciation on Mars, Nature, 434, 346-351, doi:10.1038/ nature 03359 .

Hecht, M. (2002), Metastability of liquid water on Mars, Icarus, 156, 373 386, doi:10.1006/icar.2001.6794.

Hiesinger, H., and J. Head (2000), Characteristics and origin of polygonal terrain in southern Utopia Planitia, Mars: Results from Mars Orbiter Laser Altimeter and Mars Orbiter Camera data, J. Geophys. Res., 105(E5), 11,999-12,022, doi:10.1029/1999JE001193.

Jakosky, B., B. Henderson, and M. Mellon (1995), Chaotic obliquity and the nature of the Martian climate, J. Geophys. Res., 100(E1), 1579-1584, doi:10.1029/94JE02801.

Kargel, J. S., and F. M. Costard (1993), Possible occurrence and origin of massive ice in Utopia Planitia, in Workshop on the Martian Northern Plains: Sedimentological, Periglacial, and Paleoclimatic Evolution, pp. 7-8, Lunar Planet. Inst., Houston, Tex.
Kargel, J. S., V. R. Baker, J. E. Begét, J. F. Lockwood, T. L. Péwé, J. S. Shaw, and R. G. Strom (1995), Evidence for continental glaciation in the Martian northern plains, J. Geophys. Res., 100(E3), 5351-5368, doi:10.1029/94JE02447.

Kirk, R. L., et al. (2008), Ultrahigh resolution topographic mapping of Mars with MRO HiRISE stereo images: Meter-scale slopes of candidate Phoenix landing sites, J. Geophys. Res., 113, E00A24, doi:10.1029/ 2007JE003000.

Kreslavsky, M., and J. Head (2000), Kilometer-scale roughness of Mars: Results from MOLA data analysis, J. Geophys. Res., 105(E11), 26,69526,711, doi:10.1029/2000JE001259.

Kuzmin, R. O., E. V. Zabalueva, and P. R. Christensen (2007), Analysis of the seasonal variations of TES Thermal inertia values in the mid and high latitudes of Mars, in Seventh International Conference on Mars, July 913, 2007, Pasadena CA [CD-ROM], LPI Contrib., 1353, Abstract 3022.

Lachenbruch, A. L. (1962), Mechanics of thermal contraction cracks and ice-wedge polygons in permafrost, Spec. Pap. Geol. Soc. Am., 70, 69 pp. Laskar, J., A. C. M. Correia, M. Gastineau, F. Joutel, B. Levrard, and P. Robutel (2004), Long term evolution and chaotic diffusion of the insolation quantities of Mars, Icarus, 170, 343-364, doi:10.1016/j.icarus. 2004.04.005.

Lefort, A. (2008), Formation processes of periglacial-like features in the mid-latitudes of Mars, insight from HiRISE and energy balance modelling, Ph.D. thesis, Univ. of Bern., Bern, Switzerland.

Levrard, B., F. Forget, F. Montmessin, and J. Laskar (2004), Recent ice-rich deposits formed at high latitudes on Mars by sublimation of unstable equatorial ice during low obliquity, Nature, 431, 1072-1075, doi:10. 1038/nature03055.

Levy, J., D. R. Marchant, and J. W. Head (2006), Distribution and origin of patterned ground on Mullins Valley debris-covered glacier, Antarctica: The roles of ice flow and sublimation, Antarct. Sci., 18, 385-397, doi:10.1017/S0954102006000435.

Mackay, J. R. (1980), Deformation of ice-wedges polygons, Garry Island, Northwest Territories, Pap. Geol. Surv. Can., 80-1A, 287-291.

Mackay, J. R. (1995), Ice wedges on hillslopes and landform evolution in the late quaternary, western Arctic coast, Canada, Can. J. Earth Sci., 32(8), 1093-1105.

Madeleine, J. B., F. Forget, J. W. Head, B. Levrard, and F. Montmessin (2007), Mars: A proposed climatic scenario for northern mid-latitude glaciations, Lunar Planet. Sci., XXXVIII, Abstract 1778.

Malin, M., G. Danielson, A. Ingersoll, H. Masursky, J. Veverka, M. Ravine, and T. Soulanille (1992), Mars Observer Camera, J. Geophys. Res., 97(E5), 7699-7718.

Mangold, N. (2005), High latitude patterned grounds on Mars: Classification, distribution and climatic control, Icarus, 174, 336-359, doi:10.1016/j.icarus.2004.07.030.

Mangold, N., S. Maurice, W. C. Feldman, F. Costard, and F. Forget (2004), Spatial relationships between patterned ground and ground ice detected by the Neutron Spectrometer on Mars, J. Geophys. Res., 109, E08001, doi:10.1029/2004JE002235

Marchant, D. R., A. R. Lewis, W. M. Phillips, E. J. Moore, R. A. Souchez, G. H. Denton, D. E. Sugden, N. Potter Jr., and G. P. Landis (2002), Formation of patterned ground and sublimation till over Miocene glacier ice in Beacon Valley, southern Victoria Land, Antarctica, Geol. Soc. Am. Bull., 114(6), 718-730, doi:10.1130/0016-7606(2002)114 $<0718$ :FOPGAS $>2.0$. CO; 2 .

McBride, S. A., C. C. Allen, and M. S. Bell (2005), Prospecting for Martian ice, Lunar Planet. Sci., XXXVI, Abstract 1090.

McEwen, A. S., et al. (2007a), Mars Reconnaissance Orbiter's High Resolution Imaging Science Experiment (HiRISE), J. Geophys. Res., 112, E05S02, doi:10.1029/2005JE002605.

McEwen, A., et al. (2007b), A closer look at water-related geologic activity on Mars, Science, 317(5845), 1706-1709, doi:10.1126/science.1143987.

Mellon, M. T. (1997), Small-scale polygonal features on Mars: Seasonal thermal contraction cracks in permafrost, J. Geophys. Res., 102(E11), 25,617-25,628, doi:10.1029/97JE02582.

Mellon, M. T., and B. M. Jakosky (1993), Geographic variations in the thermal and diffusive stability of ground ice on Mars, J. Geophys. Res., 98(E2), 3345-3364, doi:10.1029/92JE02355.

Mellon, M. T., and N. E. Putzig (2007), The apparent thermal inertia of layered surfaces on Mars, Lunar Planet. Sci., XXXVIII, Abstract 2184.

Mellon, M. T., W. C. Feldman, and T. H. Prettyman (2004), The presence and stability of ground ice in the southern hemisphere of Mars, Icarus, 169, 324-340, doi:10.1016/j.icarus.2003.10.022.

Melosh, H. J. (1989), Impact Cratering: A Geologic Process, 245 pp., Oxford Univ. Press, Oxford, U. K.

Milliken, R. E., and J. F. Mustard (2003), Erosional morphologies and characteristics of latitude-dependant surface mantles on Mars, in Sixth International Conference on Mars, July 20-25, 2003, Pasadena CA [CD-ROM], LPI Contrib., 1164, Abstract 3240. 
Milliken, R. E., J. F. Mustard, and D. L. Goldsby (2003), Viscous flow features on the surface of Mars: Observations from high-resolution Mars Orbiter Camera (MOC) images, J. Geophys. Res., 108(E6), 5057, doi:10.1029/2002JE002005.

Mischna, M. A., D. J. McCleese, M. I. Richardson, A. R. Vasavada, and R. J. Wilson (2003), Volatile cycling and layering on Mars: Observations, theory and modeling, in Sixth International Conference on Mars, July 20-25, 2003, Pasadena CA [CD-ROM], LPI Contrib., 1164, Abstract 3145 .

Mitrofanov, I., et al. (2002), Maps of subsurface hydrogen from the High Energy Neutron Detector, Mars Odyssey, Science, 297(5578), 78-81, doi:10.1126/science.1073616.

Morgenstern, A., E. Hauber, D. Reiss, S. van Gasselt, G. Grosse, and L. Schirrmeister (2007), Deposition and degradation of a volatile-rich layer in Utopia Planitia and implications for climate history on Mars, J. Geophys. Res., 112, E06010, doi:10.1029/2006JE002869.

Murton, J. B., P. Worsley, and J. Gozdzik (2000), Sand veins and wedges in cold aeolian environments, Ouat. Sci. Rev., 19, 899-922, doi:10.1016 S0277-3791(99)00045-1.

Mustard, J. F., C. D. Cooper, and M. K. Rifkin (2001), Evidence for recent climate change on Mars from the identification of youthful near-surface ground ice, Nature, 412, 411-414, doi:10.1038/35086515.

Mutch, T. A., R. E. Arvidson, J. W. Head, K. L. Jones, and R. S. Saunders (1976), The Geology of Mars, 400 pp., Princeton Univ. Press, Princeton, N. J.

Ollier, C. D., and A. J. Thomasson (1957), Asymmetrical valleys of the Chiltern Hills, Geogr. J., 123, 71-80, doi:10.2307/1790725.

Plescia, J. B. (2003), Amphitrites-Peneus paterae/Malea Planum geology, Lunar Planet. Sci., XXXIV, Abstract 1478.

Plug, L. J., and B. T. Werner (2002), Nonlinear dynamics of ice-wedge networks and resulting sensitivity to severe cooling, Nature, 417, 929933, doi:10.1038/nature00796.

Pollack, J. B., and O. B. Toon (1982), Quasi-periodic climate changes on Mars: A review, Icarus, 50, 259-287, doi:10.1016/0019-1035(82)90126-9.

Russell, P. S., and J. W. Head (2003), Elysium-Utopia flows as mega-lahars: A model of dike intrusion, cryosphere cracking, and water-sediment release, J. Geophys. Res., 108(E6), 5064, doi:10.1029/2002JE001995.

Searls, M. L., M. T. Mellon, R. E. Mustard, S. Martinez-Alonso, and the HiRISE Team (2007), Mid-latitude dissected mantle terrain as viewed from HiRISE, in Seventh International Conference on Mars, July 9-13, 2007, Pasadena CA [CD-ROM], LPI Contrib., 1353, Abstract 3351.

Searls, M. L., M. T. Mellon, S. Martinez-Alonso, and the HiRISE Team (2008), Slope analysis and ice stability of the mid-latitude dissected terrain on Mars, Lunar Planet. Sci., XXXIX, Abstract 2376.

Sears, D., L. Roe, and S. Moore (2005), Stability of water and gully formation on Mars, Lunar Planet. Sci., XXXVI, Abstract 1496.
Seibert, N. M., and J. S. Kargel (2001), Small-scale polygonal terrain: Implication for liquid surface water, Geophys. Res. Lett., 28(5), 899902, doi:10.1029/2000GL012093.

Sletten, R. S., B. Hallet, and R. C. Fletcher (2003), Resurfacing time of terrestrial surfaces by the formation and maturation of polygonal patterned ground, J. Geophys. Res., 108(E4), 8044, doi:10.1029/2002JE001914.

Smith, D. E., et al. (2001), Mars Orbiter Laser Altimeter: Experiment summary after the first year of global mapping of Mars, J. Geophys. Res., 106(E10), 23,689-23,722, doi:10.1029/2000JE001364.

Smith, M. D., M. J. Wolff, N. Spanovich, A. Ghosh, D. Banfield, P. R. Christensen, G. A. Landis, and S. W. Squyres (2006), One Martian year of atmospheric observations using MER Mini-TES, J. Geophys. Res. 111, E12S13, doi:10.1029/2006JE002770.

Soare, R. J., G. R. Osinski, and C. L. Roehm (2008), Thermokarst lakes and ponds on Mars in the very recent (late Amazonian) past, Earth Planet. Sci. Lett., 272(1-2), 382-393, doi:10.1016/j.epsl.2008.05.010.

Squyres, S. W., and M. H. Carr (1986), Geomorphic evidence for the distribution of ground ice on Mars, Science, 231(4735), 249-252, doi:10.1126/science.231.4735.249.

Tanaka, K. L., J. L. Skinner, T. M. Hare, T. Joyal, and A. Wenker (2003), Resurfacing history of the northern plains of Mars based on geologic mapping of Mars Global Surveyor data, J. Geophys. Res., 108(E4), 8043, doi:10.1029/2002JE001908.

Tanaka, K. L., J. A. Skinner, and T. M. Hare (2005), Geological map of the northern plains of Mars, 1:15,000,000, U.S. Geol. Surv. Misc. Invest. Ser. Map, $I-2888$.

Toon, O. B., J. B. Pollack, W. Ward, J. A. Burns, and K. Bilski (1980), The astronomical theory of climatic change on Mars, Icarus, 44, 552-607, doi:10.1016/0019-1035(80)90130-X.

Wan Bun Tseung, J. M., and R. J. Soare (2006), Thermokarst and related landforms in western Utopia Planitia, Mars: Implications for near-surface excess ice, Lunar Planet. Sci., XXXVII, Abstract 1414.

Zurek, R. W., and S. E. Smrekar (2007), An overview of the Mars Reconnaissance Orbiter (MRO) science mission, J. Geophys. Res., 112 E05S01, doi:10.1029/2006JE002701.

C. M. Dundas and A. S. McEwen, Department of Planetary Sciences, University of Arizona, Tucson, AZ 85721, USA

R. L. Kirk, Astrogeology Program, U.S. Geological Survey, 2255 N. Gemini Drive, Flagstaff, AZ 86001, USA.

A. Lefort, P. S. Russell, and N. Thomas, Space Research and Planetary Sciences, Planetary Imaging Group, Physikalisches Institut, Universität Bern, CH-3012 Bern, Switzerland. (alexandra.lefort@space.unibe.ch) 